$\underline{\text { Review }}$

\title{
The front and rear of collective cell migration
}

Roberto Mayor ${ }^{1 *}$ and Sandrine Etienne-Manneville ${ }^{2 *}$

${ }^{1}$ Department of Cell and Developmental Biology, University College London, Gower Street, London WC1E6BT, UK. E-mail: r.mayor@ucl.ac.uk

2 Institut Pasteur - CNRS UMR 3691, Cell Polarity, Migration and Cancer Unit, 25 rue du Dr Roux 75724 Paris Cedex 15, France. E-mail : setienne@pasteur.fr

* Corresponding authors

\begin{abstract}
Collective cell migration has a key role during morphogenesis, during wound healing and tissue renewal in the adult, and it is involved in cancer spreading. In addition to displaying a coordinated migratory behavior, collectively migrating cells move more efficiently than if they migrated separately, which indicates that cellular interplay occurs during collective cell migration. Over the last years, evidence has accumulated confirming the importance of such intercellular communication and exploring the molecular mechanisms involved. These mechanisms are based both on direct physical interactions which coordinate the cellular responses and on the cell collective behavior that generates an environment optimal for efficient directed migration. These studies have described how leader cells at the front of cell groups drive migration and have highlighted the importance of following cells, which communicate between them and with the leaders to improve the efficiency of collective movement.
\end{abstract}


The development of multicellular organisms involves morphogenetic movements where large groups of cells migrate in a coordinated manner to contribute to the formation of tissues and organs (Box 1) ${ }^{1}$. Collective migration also occurs in the adult during wound healing, tissue renewal and angiogenesis and has been involved in tumor spreading ${ }^{2}$ (Box 1). Elucidation of the molecular mechanisms underlying collective migration is thus fundamental not only for our understanding of morphogenetic processes but also for the identification of new therapeutic targets to prevent tumor spreading and metastasis.

During collective migration, multiple cells migrate in the same direction at a similar speed. Moreover, these cells coordinate their response to the environment, ensuring that cells that would otherwise be immobile or migrate in a different direction also follow the global movement. Thus, the major feature of a collectively migrating group of cells is that it migrates more efficiently than if cells were isolated. Although single cells have a higher instant velocity, they undergo a less persistent migration, quickly and frequently changing direction. Such collective behavior involves a physical or chemical crosstalk between individual migrating cells. In the case of cohesive groups such as the fish lateral line primordium or epithelia cell sheets (Box1), direct cell-cell contacts not only maintain the group physical integrity, they also contribute to the coordination of the motile behavior of adjacent cells. However, cranial neural crest cells and neurons in the rostral migratory stream display only transient contacts during migration (Box 1). Nevertheless collective behavior has also been observed in these loosely associated streams of cells, indicating that communication either through diffusible factors or by the local alteration of the extracellular matrix (ECM) can also promote cell coordination.

The molecular mechanisms that control single cell polarization and migration have been extensively studied and the basic mechanisms of single cell migration can be also applied to collective movement (Figure 1a,b). Single cell migration is based on the establishment of a frontto-rear polarity axis, including polarized cytoskeletal rearrangements and the polarized organization of membrane trafficking (Figure 1a). Underlying this front-to-rear functional polarization is a front-to-rear polarization of signaling cascades involving, in particular, the small GTPase proteins of the Rho family. At the front, Rac and Cdc42 induce cytoskeletal rearrangements, including rapid actin polymerization, leading to the formation of membrane protrusions such as filopodia and lamellipodia, and simultaneously promote integrin engagement 
with the extracellular matrix ${ }^{3}$ (Figure 1a). At the rear, a distinct signaling pathway involving Rho promotes acto-myosin contraction.

The same mechanisms are at play in each individual cell during collective migration of loose cell streams. However, in cohesive cell groups, cellular contacts modify the distribution of the classical features found in isolated migrating cells. The cells located at the front of the group are called leader cells (Box2). These cells sense the microenvironment and dictate the direction and speed of migration of the entire cell cluster (Figure 1c). The definition of leader and follower cells is based only on their relative position within a cell cluster, with leader and follower cells located at the front and back of the cluster, respectively. Because of their position, leader cells are exposed to higher levels of external signals such as chemoattractants and play a major role in extracellular matrix remodeling during migration. Behind leader cells, cell-cell contacts impair the formation of a classical leading edge implying that the mechanisms actually driving the migration of so-called followers must be different from that of the leader cells (Figure 1c). These followers must therefore rely on strong cellular interactions to collectively polarize. In a migrating single cell, signaling at the rear can modulate the speed and the direction of migration $4-6$

Similarly in groups of cells, follower cells can also influence the behavior of the leaders to modulate the collective movement.

In this review, we discuss our current understanding of the mechanisms underlying the collective behavior of migrating cells. We describe the fundamental role of the leader cells in sensing the microenvironment and dictating the direction and speed of movement to the cell group. We then discuss the often-overlooked role of followers, highlighting how interactions between followers and also between followers and leader cells affect individual cell behavior to maintain group integrity and to promote efficient directed collective migration.

\section{Leaders sense the microenvironment}

Although leader cells are generally localized at the front of the migrating group, cells that are not located at the periphery of the cell group can relocate to the leading front to become leaders ${ }^{7}$. 
Cells become leaders in response to external cues, which include the extracellular matrix, soluble factors and neighboring cells (Figure 1c).

\section{Interaction of leaders with the extracellular matrix}

The interaction between cells and the extracellular matrix occurs mainly through integrins, which transduce both mechanical and chemical signals. Integrin-mediated signaling responds to the composition and the stiffness of the extracellular matrix ${ }^{8,9}$. Moreover, extracellular matrix fibers control the migration of multicellular streams in vivo by providing directional cues ${ }^{10,11}$. In vitro wound healing assays have revealed that new interactions with the extracellular matrix are induced at the wound edge of the cells. These interactions trigger integrin-mediated signaling, which leads to cytoskeletal rearrangements, structural reorganization and morphological polarization, typical of leader cells ${ }^{12}$ (Figure 2).

Depending on cell types and cell substrates, several integrin dimers have been involved in collective migration. In particular, $\beta 1$ integrins are used by endothelial cells, astrocytes and epithelial cells ${ }^{13-15}$. Engagement of integrins with the extracellular matrix leads to the recruitment and activation of $\mathrm{Cdc} 42$ and/or Rac, through adapter proteins associated with GEFs (Guanosine Exchange Factors), such as Scrib and $\beta$ PIX or Par3 and TIAM- $1^{16-19}$ and intracellular kinases such as FAK and $\mathrm{Src}^{20,21}$ (Figure 2). Activation of these small GTPases promotes the extension of membrane protrusion a the cell front. Their downstream effectors, such as the Scar/Wave complex, induces the polymerization of actin filaments in the vicinity of the leading edge plasma membrane, creating pushing forces required for membrane protrusion ${ }^{22}$. Small GTPases also promotes the polarization of the microtubule network and the associated vesicular traffic ${ }^{23}$, thereby providing the cell front with additional membrane and membrane receptors (Figure 2). The polarized intracellular organization of the leader cells promotes positive feedback loops and contributes to the stabilization of the polarized cell state ${ }^{23}$.

\section{Stimulation by soluble chemotactic factors}

In vivo, collective migration is frequently promoted by soluble factors such as chemokines or growth factors (Figure 1c). For example, collective migration of endothelial cells 
is essentially driven by VEGFs (Vascular Endothelial Growth Factors) but can also be supported by bFGF and other cytokines as well as nitric oxide $(\mathrm{NO})^{24}$, which initiates the directional migration of tip cells and blood vessel formation (for reviews ${ }^{13,25}$ ). Leader cells are pivotal in sensing environmental soluble factors to promote the chemotaxis of the entire migrating cell group. In the fish lateral line primordium (Box 1), the expression of the receptor Cxcr4b, which interacts with the Sdf1 chemokine, in the leader cells is sufficient to drive collective chemotaxis $^{26}$.

Soluble factors promote the collective behavior in two different ways. First, signaling through growth factor receptors or chemokines, like signaling through integrins, induces cell polarization and protrusions. In the lateral line primordium, Sdf1 binding to Cxcr4b promotes actin-driven membrane protrusion via the heterotrimeric $G$ protein subunit $G \beta 1^{27}$. Most soluble factors activate $\mathrm{Cdc} 42$ and Rac via phosphoinositide-mediated signaling ${ }^{28,29}$ to eventually promote actin polymerization. Like in single chemotactic cells signaling through growth factors or chemokine receptors frequently acts via the polarized recruitment and activation of a PI3K and Rac positive feedback loop leading to actin rearrangements and membrane protrusion (Figure 2b). Moreover, there is an important crosstalk between tyrosine kinase receptor or G-protein coupled receptors and integrin signaling ${ }^{30,31}$. VEGF and bFGF impact on integrin signaling by regulating integrin expression or FAK phosphorylation ${ }^{32-34}$. This interplay between integrin and chemotactic receptor signaling is highlighted by the fact that collective chemotaxis requires cell adhesion to the extracellular matrix. In Dictyostelium discoideum migrating towards cAMP, inhibition of cellsubstrate interactions using polyethylene-glycol coated surfaces prevents cell streaming ${ }^{35}$. In this case, the authors had shown that loss of adhesion to the substrate does not directly affect the cytoskeletal dynamics required for cell protrusion and migration but perturbs cell-cell interactions. Conversely, integrin signaling generally potentiates growth factor receptor activity ${ }^{36}$, 37. Expression of the integrin $\alpha 6 \beta 4$ in pancreatic cancer cells increases cancer spreading and metastasis by promoting HGF-induced activation of $\operatorname{Rac}^{38}$.

Second, chemotactic factors induce intracellular signaling that ultimately controls gene expression and defines the characteristics of leader cells. D. melanogaster border cells polarize in response to PVF (PDGF-VEGF-related factor) and EGF (Epithelial growth factor) ${ }^{39}$. The cell of the group that is the most responsive to these growth factors becomes the leader. FGF stimulation 
of tracheal cells in D. melanogaster leads to the activation of MAPK followed by upregulation of its own receptor reinforcing the leader phenotype ${ }^{40,41}$. Increasing levels of FGFR signaling also upregulate Delta1 in the leader cells, which interacts with Notch situated on the membrane of followers and inhibits the FGFR-MAPK signaling cascade in these cells ${ }^{42,43}$. A similar signaling is also at play during vascular sprouting ${ }^{44,45}$ and tumor angiogenesis ${ }^{46,47}$,in vertebrates ensuring the stability of leader cell characteristics.

\section{Interactions between leaders}

When large sheets or clusters of cells are migrating, the leader cells are linked together by adhesive structures, including adherens junctions, to form a front line (Figure 1c). Cadherins are the major transmembrane component of adherens junctions. They interact and control the actin and microtubule networks via catenins, such as p120-, $\alpha$ - and $\beta$-catenin ${ }^{48,49}$. Because of their tight association with the actin cytoskeleton, adherens junctions are essential for maintaining the integrity of the migrating cell monolayer or cell group (Figure 3a). Impairing cadherin functions dramatically alters collective cell dynamics ${ }^{50}$. As observed in several systems, cells, mainly leader cells, tend to detach and migrate separately ${ }^{51-53}$. However, in border cells, loss of Ecadherin inhibits the formation of protrusions and blocks migration without any dissociation of the cell cluster ${ }^{54}$. Variation in the adherens junction molecular composition, and in particular the balance between different cadherins may be responsible for these different behaviors ${ }^{50}$. Whereas E-cadherin mediated junctions are reinforced when submitted to pulling forces, P-cadherin is not involved in the adaptation of intercellular tension ${ }^{50}$. Another possible explanation for the inhibition of migration following the loss of E-cadherin ${ }^{54}$ is based on the fact that border cells use nurse cells as their substrate. The interaction between these cell types during migration is mediated by E-cadherin, analogous to the use of integrins during migration on extracellular matrix. A similar interaction has been proposed for the migration of primordial germ cells in zebrafish $^{55}$.

Cadherin-mediated adherens junctions are also required for cell chemotaxis, suggesting that each cell, even leader cells, cannot interpret the chemotactic gradient without interacting with its neighbors (see below) (Figure 1c). Several studies have shown an antagonistic relationship 
between cadherin-mediated junctions and integrin-based adhesions ${ }^{56-58}$. Cadherin-mediated contacts are thus required for the correct polarization of the cells and for directed movement ${ }^{49}$. In fact, the anisotropic distribution of adherens junctions is sufficient to promote cell polarization ${ }^{56}$, 59 (Figure 3a). In absence of adherens junctions, integrins are constitutively engaged with the extracellular matrix along the entire cell periphery ${ }^{51}$. The protrusions form in random directions and the persistence of migration is strongly reduced ${ }^{51}$. In the case of migrating chains observed during tracheal or vascular sprouting, only one or two leader cells direct the movement and their cell-cell contacts are mostly located at the rear (Box 2). These limited contacts contribute to cell polarization by limiting the formation of protrusions and promoting cell contractility at the cell rear via contact inhibition of locomotion (see below) ${ }^{60,61}$.

Cadherin-mediated interactions with neighboring non-migrating cells also contribute to the polarization of migrating cell groups. In particular, expression of E-cadherin in nurse cells is required for the polarized movement of border cells across the egg chamber ${ }^{62}$. In contrast, overexpression of E-cadherin in nurse cells inhibits cell migration and increases the polarization of border cells in the direction of the oocyte. These results suggest that the level of cadherin expression is an essential parameter that determines whether cells must migrate on top or in between other, or whether they migrate together.

The maintenance and dynamic control of cell-cell contacts is crucial to prevent too frequent changes in leadership and to keep the cohesion of the migrating leaders and more generally of the migrating group. Adherens junctions undergo a continuous acto-myosin driven retrograde flow along the lateral sides of adjacent cells migrating in a wound healing assay ${ }^{63}$ (Figure $3 \mathrm{~b}$ ). The rearward movement of adherens junctions ends near the cell rear with the dissociation of cadherin-mediated interactions and internalization followed by recycling of cadherins towards the leading edge and formation of new junctions at the front of lateral contacts ${ }^{63}$. This dynamic treadmilling of adherens junctions makes intercellular contacts very malleable (Figure 3c), while maintaining the mechanical strength of adherens junctions between adjacent cells during migration. Adherens junctions between leaders are connected to thick actin cables and display a stretched morphology indicating that important forces are exerted between adjacent cells ${ }^{63,64}$. The cadherin complex tightly associated to the cytoskeleton via catenin adaptors can synchronize the dynamics of the actin retrograde flow in neighboring leader cells. The adherens junction- 
mediated interaction between contractile actin cables of adjacent cells can also participate in the formation of an acto-myosin cable connecting laterally all the wound edge cells (Figure 3b). When cellular sheets close a limited hole, such contractile cable can function as a purse-string to promote the convergent migration of the wound edge cells ${ }^{65}$.

\section{Transmitting information to the followers}

The role of leader cells in leading collective migration has been observed in vitro and is also clearly illustrated during several morphogenetic events as well as during cancer invasion ${ }^{66-68}$. During migration of epithelial sheets, ablating the leader cells or separating them from the followers perturbs the directionality and persistence of migration and the collective behavior, highlighting the instructive role of leader cells ${ }^{15,66}$. Leader cells not only explore the tissue environment and identify the migration path, they also significantly contribute to the directed migration of the followers.

\section{Paving the way}

As leader cells move through the 3D environment, they modify and enlarge the path of migration. Traction exerted on the extracellular matrix through acto-myosin-associated focal adhesions can affect the shape of the matrix fibers. The organization of the matrix fibers, can promote directional guidance and cell streaming ${ }^{10,}{ }^{11}$. Moreover, matrix metallo-proteases secreted by the leader cells cut and remodel extracellular matrix fibers to facilitate collective movement. For example, FGF-stimulated leader tracheal cells in Drosophila secrete MMP2. MMP2 secretion contributes to the inhibition of FGFR-MAPK signaling in followers. In embryos lacking MMP2, the stability of the leaders is compromised and new tip cells emerge from the FGF-stimulated followers, prompting tracheal defects ${ }^{40,69}$. Moreover, carcinoma invasion is promoted by the migration of stromal fibroblast leaders that generate migratory tracks that exert least resistance to migration ${ }^{70}$.

Secretion of extracellular matrix components by leader cells can also drastically change the composition of the matrix, so that the followers migrate on a substrate that is different both in 
structure and in nature from the initial substratum met by the leaders. The changes in substrate composition and of the nature of the engaged integrins impact on the migratory behavior of the followers increasing the polarized organization of the cell group ${ }^{14,71}$.

\section{Leaders and followers join their forces}

Leader cells can generate most of the traction forces that drag the followers behind ${ }^{72}$. Focal adhesions at the front of leader cells mature and associate with acto-myosin cables to promote the contraction of the cell body. Detailed analysis of traction forces and small GTPase activities showed a clear accumulation of traction forces associated with an elevated RhoA activity at the wound edge of epithelial sheets ${ }^{73}$. These forces are transmitted via longitudinal acto-myosin cables to several rows of followers ${ }^{73,74}$. In Drosophila border cells, analysis of the forces exerted on cadherins shows that the tension decreases from the front of the cluster to the rear $^{62}$. Transmission of forces would thus allow, in principle, leader cells at the edge of a monolayer to drag a relatively passive mass of follower cells. However, this coordinated movement not only involves a mechanical coupling between cells, but also the ability of cells to sense the exerted forces.

The capacity of follower cells to respond to the forces exerted by the preceding cells depends on a process known as mechanosensing ${ }^{75,76}$. Cells sense the physical properties, in particular the rigidity of their microenvironment through adhesive structures such as focal adhesions and adherens junctions. This mechanosensing is mediated by the force-induced conformational changes of key proteins acting as mechanotransducers. These molecules, like talin in focal adhesion and $\alpha$-catenin in adherens junctions, are key players in bridging the transmembrane adhesion receptor (integrin and cadherin) to the actin cytoskeleton and are thus submitted to forces exerted between the acto-myosin contractile network and the extracellular environment. Mechanotransducers undergo a conformational change upon stretching, revealing new protein interaction domains and inducing biochemical signaling, which in turn can modulate the strength of adhesion. Cell-cell contact associated Merlin has recently been involved in mechanotranduction during collective migration ${ }^{77}$. Pulling forces exerted by leader cells promote the translocation of Merlin from cell-cell contacts to the cell cytoplasm to support the 
polarization of Racl activation and lamellipodium formation defining the front side of the following cells ${ }^{77}$. In addition, tension exerted on C-cadherin-mediated junctions leads to the reinforcement of desmosomes ${ }^{78}$. In this case, this reinforcement involves interplay between cadherin and integrin signaling ${ }^{79}$. At the molecular level, a common aspect of mechanosensing relies on protein conformational changes. For example, under tension $\alpha$-catenin undergoes a conformational change that exposes an intramolecular interaction domain, thereby enabling it to bind to vinculin, which results in increased junctional stability ${ }^{80,81}$. In a similar way, tension seems to stabilize the binding of $\alpha$-catenin to actin, thereby linking external mechanical forces to the cytoskeleton ${ }^{82,83}$. It is also possible that forces alone may directly polarize cells without interfering with signaling pathways.

Followers can also directly participate to pulling forces ${ }^{26,84}$. It has been shown that stress builds up within the monolayer several cell rows away from the leading edge, which cannot be explained if forces are generated by leader cells alone. The mechanism proposed to explain this observation is based on a long-range transmission of forces across intercellular adhesions resulting in an increased tension or "tug of war" between leaders and follower cells ${ }^{84-86}$. These observations suggest that force generation does not depend solely on leader cells, but followers also exert traction and play an important role in organizing collective cell migration (see below). Overall the role of leaders and followers and their contribution to forces in collective cell migration is still controversial.

\section{Followers, not just following}

Most of the research to understand how directionality is achieved in collective cell migration has focused on what happens at the front of a cell cluster; however, recent findings have shown that follower cells are required for efficient migration. The followers are essential for the polarization of the entire cell cluster by controlling the role of the leaders, indirectly influencing their polarization, and also by participating in gradient sensing and chemotaxis.

\section{Discussing the leadership with the followers}


As a cell group migrates through a complex microenvironment, the position of leader cells can be challenged. Leaders and followers can exchange places and roles during migration in vitro as well as in vivo ${ }^{87,88}$. Tip cells in tracheal branches in D. melanogaster remain stable during the

entire morphogenesis process ${ }^{89}$, whereas the leaders of border cells frequently change ${ }^{90,91}$. Despite these variations, the position of leader cells remains generally stable for several hours or longer $^{92,93}$.

The dynamic control of leadership is the result of a continuous crosstalk between leaders and followers, which has been particularly well studied in D. melanogaster border cells. Activation of Rac has been shown to be both necessary and sufficient to induce the leader cell behavior and collective migration indicating that collective guidance results from a higher level of signaling in the leader cells ${ }^{94,95}$. However, in such a small cell cluster where receptor activation is almost identical in all cells, peripheral cells have an inherent free edge and can intrinsically polarize towards this free side ${ }^{96}$. Additional signals are in this case essential to coordinate the polarization of the cluster, so that Rac activity and cell protrusions are distributed in a clearly polarized manner between the front and the rear of the cell cluster ${ }^{91,97}$. Cells adjacent to the leader restrict the activation of Rac in the leader cell. Although Rab11 and moesin have been shown to be involved, the exact mechanism which prevents Rac activation in follower cells remains to be clarified but is likely to involve direct cell-cell interactions ${ }^{98}$.

\section{Followers polarize leader cells via contact inhibition of locomotion}

During collective cell migration leader cells become polarized, with large protrusions in the direction of migration (Box 2). A concept that has recently emerged regarding collective cell migration is that follower cells play an essential role on the movement of the cluster by inducing polarization in the leader cells via the phenomenon of contact inhibition of locomotion (CIL).

CIL is the process by which upon collision between two migrating cells, they halt their forward locomotion by collapsing protrusions at the site of contact and establishing protrusions away from each other ${ }^{99-103}$ (Figure 4a).It has been proposed that, during collective cell migration, CIL ensures the absence of protrusions at points of cell-cell contacts between leading cells and followers, and simultaneously promotes the formation and maintenance of protrusions in the 
leader cells in a direction away from their contact with follower cells ${ }^{101,103}$. There is a wide variety of examples where collective cell migration has been observed in vivo (Box 1). In all these examples major protrusions are observed at the leading edge pointing away from the contact with the follower cells (Figure 1), which is the landmark of cell polarization induced by CIL $^{100-102}$. Thus, CIL between leader and follower cells appears to be a fundamental aspect of collective cell migration.

The molecular basis of CIL can be separated into three core cellular mechanisms (Figure 4b). First, cells need to sense the contact with other cells. Second, a signal needs to be transmitted from the surface to inside the cell. Third, these intracellular signals need to drive protrusion collapse at the cell contact and repolarization with new protrusions away from the cell contact. Cell surface molecules involved in CIL include cadherins (N-cadherin; Cadherin-11; ${ }^{104-106}$ ), Ephrins/Eph receptors (EphA, Ephrin-A; $\left.{ }^{107-109}\right)$, members of the Planar Cell Polarity (PCP) pathway (Frizzled 7, Wnt11, PTK7; ${ }^{110}, 111$ ), Syndecan $4{ }^{112}$ and PTK7 ${ }^{113}$. Cadherins and Ephrins mediate, respectively, a homophilic or heterophilic interaction between colliding cells via their extracellular domains. The nature of the interaction across neighbor cells for the PCP proteins. Syndecan4 and PTK7 is not completely clear, but evidence suggests that all PCP components are accumulated and activated at the site of cell contact, including the secreted ligand Wnt11, and that Syndecan4 and PTK7 work as co-receptors for the PCP signaling pathways ${ }^{110,112,114-118 .}$ This activation of PCP signaling at the site of contact leads to the recruitment of other PCP proteins, such as Disheveled, Strabismus and Prickled ${ }^{110}$, whereas cadherin engagement leads to the recruitment of Par3 at the site of cell-cell contact ${ }^{119}$.

Activation of cell surface proteins in turn leads to the activation of signaling pathways inside the cell. Despite their heterogeneity, molecules involved in the initial cell-cell contacts are generally

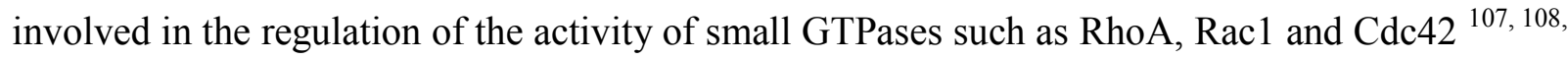
110,119-121, via the activity of the exchange factors Trio and Vav2 ${ }^{108,119,122 .}$

It has become clear that upon cell-cell contact, RhoA becomes activated at the site of contact, while Rac1 and Cdc42 are inhibited at the contact but activated at locales away from it. Actin polymerization is, in turn, controlled by the activity of these GTPases and is required for protrusion formation ${ }^{22}$. Indeed, the actin-binding protein calponin2, that works downstream of RhoA and Rac, and changes in actin flow have been shown to be involved in CIL $^{123,124}$. As a 
consequence of RhoA and Rac repolarization, microtubules and microfilaments collapse $\mathrm{e}^{119,123}$ and focal adhesions disassemble at the site of cell-cell contact ${ }^{125}$. This is accompanied by an increase in tension at the cell-cell contact followed by a rapid actomyosin contraction ${ }^{123}$, causing protrusion collapse.

New protrusions away from the cell contact could be generated by the localized regulation of small $\mathrm{G}$ proteins at the contact site that uncouples the front and the back of a cell ${ }^{126}$. Another possibility is that a chemical or a mechanical signal is transmitted from the region of cell-cell contact to the other end of the cell. It has been shown that the mechanical force generated by pulling a cell is sufficient to promote the formation of cell protrusions at the opposite end ${ }^{78}$. Although experimental evidence strongly supports the notion that CIL plays a key role in collective cell migration and mathematical models have been developed that support this concept $^{121,127-129}$, a systematic study of the molecular basis of CIL in collective cell migration is still lacking.

An intriguing idea based on the notion that cells are polarized at the edge of a cluster via CIL is that an equivalent polarization should be expected at the back and front of the cluster as in both regions cells have a free edge and are in contact with neighbor cells. Indeed, it has been shown that back and front cells are equally polarized away from the contact in border cells and neural crest cells $91,94,104,130$. The morphology and general behavior is similar in edge cells at the back or front of the cluster: both produce protrusions away from the cell-cell contact exhibiting polarized Rac1 activity; however the size and stability of protrusions and Rac1 activity tend to be higher at the front as they sense higher levels of chemoattractants. The result of this asymmetry is that the whole cluster moves forward regardless of the polarity of the cells at the back of the cluster.

\section{Followers contribute to chemotaxis}

It has been found that, in every in vivo system in which collective cell migration has been studied, chemotaxis is an important component in determining directionality. In order to maintain a gradient during chemotaxis, a "source and sink" for the chemical are required ${ }^{131}$; however in recent years a more dynamic version of the gradient has emerged, in which cells can generate 
their own gradient. This seems to be the case during collective cell migration, where follower cells in a cluster play an essential role in generating this gradient, so that some cells respond more efficiently to chemoattractants when they are part of a cluster than as single cells, suggesting again that leaders need followers to respond to external signals ${ }^{104,132}$.

This notion is supported by studies on the migration of the lateral line of zebrafish embryos (Figure 5a). The chemoattractant Sdf1 is expressed in cells prefiguring the track on which lateral line primordium migrates, but Sdf1 is expressed uniformly and not as a gradient ${ }^{133,134}$. While the Sdf1 receptor Cxcr4b is expressed throughout the primordium, a second receptor Cxcr7 is expressed only at the rear ${ }^{93}$. It has been shown that Cxcr7b binds Sdf1, functioning as a sink and thereby generating a gradient across the primordium ${ }^{135-138}$. A similar mechanism for a selfgenerated chemotactic gradient has recently being shown for the migration of melanoma cell (Figure 5c) ${ }^{139}$. Lysophosphatidic acid (LPA) functions as a strong attractant for melanoma cells, which at the same time break down LPA, generating a gradient with low LPA in the tumor and high LPA outside. This self-generated gradient around the melanomas prompts the tumor cells to migrate away from the tumor and out into the surrounding skin and blood vessels ${ }^{139}$.

A different mechanism of self-generated chemoattractant gradient formation is found in the migrating neural crest cell in Xenopus laevis embryos (Figure 5b). The neural crest is able to respond to the chemoattractant $\operatorname{Sdf} 1^{140,141}$, which is expressed by a group of epithelial cells, called placodes, which are initially adjacent to the neural crest. Neural crest cells are attracted towards the Sdf1 produced by the placodes, but upon contact between the two cell types, CIL drives the placodal cells to move away from the neural crest. This drives the placodal cells further ahead of the neural crest cells, while maintaining the attraction of the neural crest towards the Sdf1 produced by the placodes ${ }^{125}$. This mechanism of dynamic attraction and repulsion ensures effective directional migration of both cell types.

Taken together, these examples illustrate that a common mechanism driving collective cell migration is the generation of a chemotactic gradient, and that this gradient is formed by the action of the follower cells in the cluster. This last example of interaction between two distinct populations of cells to generate directional migration is not uncommon. Potentially similar mechanisms are observed in the interactions between the ureteric bud and the metanephric mesenchyme mediated by GDNF (Glial cell-Derived Neurotrophic Factor) ${ }^{142}$, between the 
anterior and posterior regions of the primordium lateral line mediated by $\mathrm{FGF}^{143}$ and between stroma fibroblasts and tumor cells ${ }^{144,145}$ (for a discussion see ${ }^{146}$ ).

\section{Conclusions and perspective}

Collective cell migration is essential for morphogenetic movements as well as for tumor spreading. Collective migration is more than just the coordinated behavior of a group of cells, as it improves the migratory capacities of each individual cell to induce a movement that is faster and more directed. At the front of migrating cell groups, leader cells play a pivotal role in driving collective movement. Despite their crucial role in controlling collective migration and therefore their implication in tumor spreading, the mechanisms leading to the emergence of leader cells and the molecular specificities of these cells remain unclear. Deciphering these signals will help us better understand how invasive cells can arise from non-migrating tissues. The leaders integrate signals coming not only from their physical microenvironment but also from the messages sent by neighboring cells. This is where the so-called followers are in fact active participant in the control of the migration speed and direction. Over the last years, several reports have shown the variety of information that can be transmitted by the followers through direct contact, exchange of soluble factors, and also through the modification of the microenvironment. This suggests that the behavior of leader cells in a group of migrating cells is in large part the result of what is occurring at the rear and that deciphering the intercellular signals exchanged within the cell group may point out new ways to promote or inhibit collective migration.

\section{Acknowledgments}

RM work was supported by grants from the Medical Research Council (J000655, M010465) and BBSRC (M008517) and SE-M work was supported by the Institut National du Cancer, l'Association pour la Recherche contre le Cancer, and La Ligue contre le Cancer. 


\section{$\underline{\text { References: }}$}

1. Weijer, C.J. Collective cell migration in development. J Cell Sci 122, 3215-23 (2009).

2. Friedl, P. \& Gilmour, D. Collective cell migration in morphogenesis, regeneration and cancer. Nat Rev Mol Cell Biol 10, 445-57 (2009).

3. Pollard, T.D. \& Cooper, J.A. Actin, a central player in cell shape and movement. Science 326, 1208-12 (2009).

4. Vicente-Manzanares, M., Ma, X., Adelstein, R.S. \& Horwitz, A.R. Non-muscle myosin II takes centre stage in cell adhesion and migration. Nat Rev Mol Cell Biol 10, 778-90 (2009).

5. Worthylake, R.A. \& Burridge, K. RhoA and ROCK promote migration by limiting membrane protrusions. J Biol Chem 278, 13578-84 (2003).

6. Worthylake, R.A., Lemoine, S., Watson, J.M. \& Burridge, K. RhoA is required for monocyte tail retraction during transendothelial migration. J Cell Biol 154, 147-60 (2001).

7. Poujade, M. et al. Collective migration of an epithelial monolayer in response to a model wound. Proc Natl Acad Sci U S A 104, 15988-93 (2007).

8. Boettiger, D. Mechanical control of integrin-mediated adhesion and signaling. Curr Opin Cell Biol 24, 592-9 (2012).

9. Dabiri, B.E., Lee, H. \& Parker, K.K. A potential role for integrin signaling in mechanoelectrical feedback. Prog Biophys Mol Biol 110, 196-203 (2012).

10. Alexander, S., Koehl, G.E., Hirschberg, M., Geissler, E.K. \& Friedl, P. Dynamic imaging of cancer growth and invasion: a modified skin-fold chamber model. Histochem Cell Biol 130, 1147-54 (2008).

11. Ventre, M., Causa, F. \& Netti, P.A. Determinants of cell-material crosstalk at the interface: towards engineering of cell instructive materials. $J R$ Soc Interface 9, 2017-32 (2012).

12. Etienne-Manneville, S. \& Hall, A. Integrin-mediated activation of Cdc42 controls cell polarity in migrating astrocytes through PKCzeta. Cell 106, 489-98 (2001).

13. Lamalice, L., Le Boeuf, F. \& Huot, J. Endothelial cell migration during angiogenesis. Circ Res 100, 782-94 (2007).

14. Peng, H., Ong, Y.M., Shah, W.A., Holland, P.C. \& Carbonetto, S. Integrins regulate centrosome integrity and astrocyte polarization following a wound. Dev Neurobiol 73, 333-53 (2013).

15. Yamaguchi, N., Mizutani, T., Kawabata, K. \& Haga, H. Leader cells regulate collective cell migration via Rac activation in the downstream signaling of integrin betal and PI3K. Sci Rep 5, 7656 (2015).

In this work, the authors show the functionnal specificity of the leader cells during the migration of an epithelial cell sheet by using micromanipulation. The crucial role of leader cells in driving the monolayer migration is associated with the activation of $\beta 1$ integrins, Rac and PI3K speicifically in these cells.

16. Osmani, N., Peglion, F., Chavrier, P. \& Etienne-Manneville, S. Cdc42 localization and cell polarity depend on membrane traffic. J Cell Biol 191, 1261-9 (2010). 
17. Osmani, N., Vitale, N., Borg, J.P. \& Etienne-Manneville, S. Scrib Controls Cdc42 Localization and Activity to Promote Cell Polarization during Astrocyte Migration. Curr Biol 16, 2395-405 (2006).

18. Ellenbroek, S.I., Iden, S. \& Collard, J.G. The Rac activator Tiam1 is required for polarized protrusional outgrowth of primary astrocytes by affecting the organization of the microtubule network. Small GTPases 3, 4-14 (2012).

19. Pegtel, D.M. et al. The Par-Tiam1 complex controls persistent migration by stabilizing microtubule-dependent front-rear polarity. Curr Biol 17, 1623-34 (2007).

20. Lawson, C.D. \& Burridge, K. The on-off relationship of Rho and Rac during integrinmediated adhesion and cell migration. Small GTPases 5, e27958 (2014).

21. Scales, T.M. \& Parsons, M. Spatial and temporal regulation of integrin signalling during cell migration. Curr Opin Cell Biol 23, 562-8 (2011).

22. Krause, M. \& Gautreau, A. Steering cell migration: lamellipodium dynamics and the regulation of directional persistence. Nat Rev Mol Cell Biol 15, 577-90 (2014).

23. Etienne-Manneville, S. Microtubules in cell migration. Annu Rev Cell Dev Biol 29, 47199 (2013).

24. Priya, M.K. et al. Tipping off endothelial tubes: nitric oxide drives tip cells. Angiogenesis (2014).

25. Chauvet, S., Burk, K. \& Mann, F. Navigation rules for vessels and neurons: cooperative signaling between VEGF and neural guidance cues. Cell Mol Life Sci 70, 1685-703 (2013).

26. Haas, P. \& Gilmour, D. Chemokine signaling mediates self-organizing tissue migration in the zebrafish lateral line. Dev Cell 10,673-80 (2006).

27. $\mathrm{Xu}, \mathrm{H}$. et al. Gbeta1 controls collective cell migration by regulating the protrusive activity of leader cells in the posterior lateral line primordium. Dev Biol 385, 316-27 (2014).

28. Barber, M.A. \& Welch, H.C. PI3K and RAC signalling in leukocyte and cancer cell migration. Bull Cancer 93, E44-52 (2006).

29. Kolsch, V., Charest, P.G. \& Firtel, R.A. The regulation of cell motility and chemotaxis by phospholipid signaling. J Cell Sci 121, 551-9 (2008).

30. Guo, W. \& Giancotti, F.G. Integrin signalling during tumour progression. Nat Rev Mol Cell Biol 5, 816-26 (2004).

31. Shen, B., Delaney, M.K. \& Du, X. Inside-out, outside-in, and inside-outside-in: G protein signaling in integrin-mediated cell adhesion, spreading, and retraction. Curr Opin Cell Biol 24, 600-6 (2012).

32. Le Boeuf, F., Houle, F., Sussman, M. \& Huot, J. Phosphorylation of focal adhesion kinase (FAK) on Ser732 is induced by rho-dependent kinase and is essential for proline-rich tyrosine kinase-2-mediated phosphorylation of FAK on Tyr407 in response to vascular endothelial growth factor. Mol Biol Cell 17, 3508-20 (2006).

33. Avraham, H.K. et al. Vascular endothelial growth factor regulates focal adhesion assembly in human brain microvascular endothelial cells through activation of the focal adhesion kinase and related adhesion focal tyrosine kinase. J Biol Chem 278, 36661-8 (2003).

34. Sieg, D.J. et al. FAK integrates growth-factor and integrin signals to promote cell migration. Nat Cell Biol 2, 249-56 (2000).

35. Wang, C. et al. The interplay of cell-cell and cell-substrate adhesion in collective cell migration. J R Soc Interface 11, 20140684 (2014). 
36. Byzova, T.V. et al. A mechanism for modulation of cellular responses to VEGF: activation of the integrins. Mol Cell 6, 851-60 (2000).

37. Kuwada, S.K. \& Li, X. Integrin alpha5/beta1 mediates fibronectin-dependent epithelial cell proliferation through epidermal growth factor receptor activation. Mol Biol Cell 11, 2485-96 (2000).

38. Cruz-Monserrate, Z. \& O'Connor, K.L. Integrin alpha 6 beta 4 promotes migration, invasion through Tiam1 upregulation, and subsequent Rac activation. Neoplasia 10, 40817 (2008).

39. Montell, D.J., Yoon, W.H. \& Starz-Gaiano, M. Group choreography: mechanisms orchestrating the collective movement of border cells. Nat Rev Mol Cell Biol 13, 631-45 (2012).

40. Ghabrial, A.S. \& Krasnow, M.A. Social interactions among epithelial cells during tracheal branching morphogenesis. Nature 441, 746-9 (2006).

41. Pocha, S.M. \& Montell, D.J. Cellular and molecular mechanisms of single and collective cell migrations in Drosophila: themes and variations. Annu Rev Genet 48, 295-318 (2014).

42. Vincent, S., Wilson, R., Coelho, C., Affolter, M. \& Leptin, M. The Drosophila protein Dof is specifically required for FGF signaling. Mol Cell 2, 515-25 (1998).

43. Ikeya, T. \& Hayashi, S. Interplay of Notch and FGF signaling restricts cell fate and MAPK activation in the Drosophila trachea. Development 126, 4455-63 (1999).

44. Hellstrom, M. et al. Dl14 signalling through Notch1 regulates formation of tip cells during angiogenesis. Nature 445, 776-80 (2007).

45. Siekmann, A.F. \& Lawson, N.D. Notch signalling limits angiogenic cell behaviour in developing zebrafish arteries. Nature 445, 781-4 (2007).

46. Noguera-Troise, I. et al. Blockade of Dll4 inhibits tumour growth by promoting nonproductive angiogenesis. Nature 444, 1032-7 (2006).

47. Ridgway, J. et al. Inhibition of D114 signalling inhibits tumour growth by deregulating angiogenesis. Nature 444, 1083-7 (2006).

48. Etienne-Manneville, S. Control of polarized cell morphology and motility by adherens junctions. Semin Cell Dev Biol 22, 850-7 (2011).

49. Etienne-Manneville, S. Adherens junctions during cell migration. Subcell Biochem 60, 225-49 (2012).

50. Bazellieres, E. et al. Control of cell-cell forces and collective cell dynamics by the intercellular adhesome. Nat Cell Biol 17, 409-20 (2015).

In this study, the authors identify three groups of molecules involved in different mechanical responses by performing an siRNA screen targetting molecules of cellcell interactions. Desmosome, tight junctions and adherens junction proteins play distinct role in the maintenance and the adaptation of the eptihelial monolayer mechanics. They also distinguish N-, P and E-cadherin functions in the regulation of intercellular tension equilibrium and intercellular tension response to extracellular forces.

51. Camand, E., Peglion, F., Osmani, N., Sanson, M. \& Etienne-Manneville, S. N-cadherin expression level modulates integrin-mediated polarity and strongly impacts on the speed and directionality of glial cell migration. $J$ Cell Sci 125, 844-57 (2012).

52. Liu, Q. et al. Cell adhesion molecule cadherin-6 function in zebrafish cranial and lateral line ganglia development. Dev Dyn 240, 1716-26 (2011). 
53. Wilson, A.L. et al. Cadherin-4 plays a role in the development of zebrafish cranial ganglia and lateral line system. Dev Dyn 236, 893-902 (2007).

54. Niewiadomska, P., Godt, D. \& Tepass, U. DE-Cadherin is required for intercellular motility during Drosophila oogenesis. J Cell Biol 144, 533-47 (1999).

55. Kardash, E. et al. A role for Rho GTPases and cell-cell adhesion in single-cell motility in vivo. Nat Cell Biol 12, 47-53; sup pp 1-11 (2010).

56. Dupin, I., Camand, E. \& Etienne-Manneville, S. Classical cadherins control nucleus and centrosome position and cell polarity. J Cell Biol 185, 779-86 (2009).

57. Borghi, N., Lowndes, M., Maruthamuthu, V., Gardel, M.L. \& Nelson, W.J. Regulation of cell motile behavior by crosstalk between cadherin- and integrin-mediated adhesions. Proc Natl Acad Sci U S A (2010).

58. Burute, M. \& Thery, M. Spatial segregation between cell-cell and cell-matrix adhesions. Curr Opin Cell Biol 24, 628-36 (2012).

59. Desai, R.A., Gao, L., Raghavan, S., Liu, W.F. \& Chen, C.S. Cell polarity triggered by cell-cell adhesion via E-cadherin. J Cell Sci 122, 905-11 (2009).

60. Carmona-Fontaine, C. et al. Contact inhibition of locomotion in vivo controls neural crest directional migration. Nature 456, 957-61 (2008).

This paper describes for the first time that contact inhibition of locomotion takes place in vivo, and it prose a molecular mechanism based on regulation os Small GTPases at the cell contact via PCP signaling.

61. Abraham, S. et al. VE-Cadherin-mediated cell-cell interaction suppresses sprouting via signaling to MLC2 phosphorylation. Curr Biol 19, 668-74 (2009).

62. Cai, D. et al. Mechanical feedback through E-cadherin promotes direction sensing during collective cell migration. Cell 157, 1146-59 (2014).

The authors characterize the wroles of E-cadherin-mediated interaction during the migration of border cells between nurse cells in the $D$. melanogaster oocyte. Contacts of border cells with nurse cells, polar cells or other border cells each have specific effects on controling the polarity and migration of the cell group.

63. Peglion, F., Llense, F. \& Etienne-Manneville, S. Adherens junction treadmilling during collective migration. Nat Cell Biol 16, 639-51 (2014).

This study shows that the dynamics of adherens junctions between leader cells in a woundinduced collective migration plays a key role in the control of collective migration. Adherens junctions of the lateral sides of the cells follow a continuous retrograde flow which is compensated by a p120Ctn-regulated polarized traffic of cadherins.

64. Omelchenko, T., Vasiliev, J.M., Gelfand, I.M., Feder, H.H. \& Bonder, E.M. Rhodependent formation of epithelial "leader" cells during wound healing. Proc Natl Acad Sci $U S A$ 100, 10788-93 (2003).

65. Jacinto, A. et al. Dynamic analysis of actin cable function during Drosophila dorsal closure. Curr Biol 12, 1245-50 (2002).

66. Reffay, M. et al. Orientation and polarity in collectively migrating cell structures: statics and dynamics. Biophys $J$ 100, 2566-75 (2011).

67. Aigouy, B., Lepelletier, L. \& Giangrande, A. Glial chain migration requires pioneer cells. $J$ Neurosci 28, 11635-41 (2008). 
68. Khalil, A.A. \& Friedl, P. Determinants of leader cells in collective cell migration. Integr Biol (Camb) 2, 568-74 (2010).

69. Wang, Q., Uhlirova, M. \& Bohmann, D. Spatial restriction of FGF signaling by a matrix metalloprotease controls branching morphogenesis. Dev Cell 18, 157-64 (2010).

70. Gaggioli, C. et al. Fibroblast-led collective invasion of carcinoma cells with differing roles for RhoGTPases in leading and following cells. Nat Cell Biol 9, 1392-400 (2007).

71. Nguyen, B.P., Ryan, M.C., Gil, S.G. \& Carter, W.G. Deposition of laminin 5 in epidermal wounds regulates integrin signaling and adhesion. Curr Opin Cell Biol 12, 554-62 (2000).

72. Caussinus, E., Colombelli, J. \& Affolter, M. Tip-cell migration controls stalk-cell intercalation during Drosophila tracheal tube elongation. Curr Biol 18, 1727-34 (2008).

73. Reffay, M. et al. Interplay of RhoA and mechanical forces in collective cell migration driven by leader cells. Nat Cell Biol 16, 217-23 (2014).

In this paper the authors map the mechanical traction forces exerted on the surface by MDCK migration fingers, and correlate them with RhoA activity. They show that these fingers are mechanical global entities with the leader cells exerting a large traction force and dragging the whole structure.

74. Li, L. et al. E-cadherin plays an essential role in collective directional migration of large epithelial sheets. Cell Mol Life Sci 69, 2779-89 (2012).

75. Ladoux, B. \& Nicolas, A. Physically based principles of cell adhesion mechanosensitivity in tissues. Rep Prog Phys 75, 116601 (2012).

76. Pruitt, B.L., Dunn, A.R., Weis, W.I. \& Nelson, W.J. Mechano-transduction: from molecules to tissues. PLoS Biol 12, e1001996 (2014).

77. Das, T. et al. A molecular mechanotransduction pathway regulates collective migration of epithelial cells. Nat Cell Biol 17, 276-87 (2015).

The authors identify Merlin as an essential mechanotranducer. Its localization is affected by intercellular pulling forces and its relocalization to the cytoplasm induces the polarization of Rac activity, lamellipodia formation and directed migration. Merlin thereby directly participate in collective migration by promoting directional migration in follower cells.

78. Weber, G.F., Bjerke, M.A. \& DeSimone, D.W. A mechanoresponsive cadherin-keratin complex directs polarized protrusive behavior and collective cell migration. Dev Cell 22, 104-15 (2012).

79. Bjerke, M.A., Dzamba, B.J., Wang, C. \& DeSimone, D.W. FAK is required for tensiondependent organization of collective cell movements in Xenopus mesendoderm. Dev Biol 394, 340-56 (2014).

80. Yonemura, S. A mechanism of mechanotransduction at the cell-cell interface: emergence of alpha-catenin as the center of a force-balancing mechanism for morphogenesis in multicellular organisms. BioEssays 33, 732-6 (2011).

81. Yonemura, S., Wada, Y., Watanabe, T., Nagafuchi, A. \& Shibata, M. alpha-Catenin as a tension transducer that induces adherens junction development. Nat Cell Biol 12, 533-42 (2010).

82. Buckley, C.D. et al. Cell adhesion. The minimal cadherin-catenin complex binds to actin filaments under force. Science 346, 1254211 (2014).

This paper address a long standing question: how is the interaction between the cadherincatenin complex and F-actin. Using an optical trap-based assay, the authors show that force 
promotes the interaction between the adhesion complex and actin, explaining how the adherens junction transduce mechanical forces

83. Leckband, D.E. \& de Rooij, J. Cadherin adhesion and mechanotransduction. Annu Rev Cell Dev Biol 30, 291-315 (2014).

84. Trepat, X. et al. Physical forces during collective cell migration. Nat. Phys. 5, 426-430 (2009).

This paper shows show for the first time that tractions forces arise many cell rows behind the leading front edge and extend across enormous distances. These findings suggest that forces generated by leader cell are a small part of a global tug-of-war involving cells well back from the leading edge.

85. Trepat, X. \& Fredberg, J.J. Plithotaxis and emergent dynamics in collective cellular migration. Trends Cell Biol 21, 638-46 (2011).

86. Tambe, D.T. et al. Collective cell guidance by cooperative intercellular forces. Nat Mater 10, 469-75 (2011).

This work analysis the forces involved during collective cell migration of epithelial cell sheets. It shows that cells are able to transmit normal stress across the cell-cell junction, but they migrate along orientations of minimal intercellular shear stress.

87. Arima, S. et al. Angiogenic morphogenesis driven by dynamic and heterogeneous collective endothelial cell movement. Development 138, 4763-76 (2011).

88. Jakobsson, L. et al. Endothelial cells dynamically compete for the tip cell position during angiogenic sprouting. Nat Cell Biol 12, 943-53 (2010).

89. Lebreton, G. \& Casanova, J. Specification of leading and trailing cell features during collective migration in the Drosophila trachea. J Cell Sci 127, 465-74 (2014).

90. Bianco, A. et al. Two distinct modes of guidance signalling during collective migration of border cells. Nature 448, 362-5 (2007).

91. Prasad, M. \& Montell, D.J. Cellular and molecular mechanisms of border cell migration analyzed using time-lapse live-cell imaging. Dev Cell 12, 997-1005 (2007).

92. Friedl, P. et al. Migration of coordinated cell clusters in mesenchymal and epithelial cancer explants in vitro. Cancer Res 55, 4557-60 (1995).

93. Aman, A. \& Piotrowski, T. Wnt/beta-catenin and Fgf signaling control collective cell migration by restricting chemokine receptor expression. Dev Cell 15, 749-61 (2008).

94. Wang, X., He, L., Wu, Y.I., Hahn, K.M. \& Montell, D.J. Light-mediated activation reveals a key role for Rac in collective guidance of cell movement in vivo. Nat Cell Biol 12, 591-7 (2010).

95. Inaki, M., Vishnu, S., Cliffe, A. \& Rorth, P. Effective guidance of collective migration based on differences in cell states. Proc Natl Acad Sci U S A 109, 2027-32 (2012).

96. Janssens, K., Sung, H.H. \& Rorth, P. Direct detection of guidance receptor activity during border cell migration. Proc Natl Acad Sci U S A 107, 7323-8 (2010).

97. Poukkula, M., Cliffe, A., Changede, R. \& Rorth, P. Cell behaviors regulated by guidance cues in collective migration of border cells. J Cell Biol 192, 513-24 (2011).

98. Ramel, D., Wang, X., Laflamme, C., Montell, D.J. \& Emery, G. Rab11 regulates cell-cell communication during collective cell movements. Nat Cell Biol 15, 317-24 (2013). 
99. Abercrombie, M. \& Heaysman, J.E. Observations on the social behaviour of cells in tissue culture. I. Speed of movement of chick heart fibroblasts in relation to their mutual contacts. Exp Cell Res 5, 111-31 (1953).

100. Abercrombie, M. Contact inhibition in tissue culture. In Vitro 6, 128-42 (1970).

101. Mayor, R. \& Carmona-Fontaine, C. Keeping in touch with contact inhibition of locomotion. Trends Cell Biol 20, 319-28 (2010).

102. Stramer, B.M., Dunn, G.A., Davis, J.R. \& Mayor, R. Rediscovering contact inhibition in the embryo. J Microsc 251, 206-11 (2013).

103. Theveneau, E. \& Mayor, R. Collective cell migration of the cephalic neural crest: the art of integrating information. Genesis 49, 164-76 (2011).

104. Theveneau, E. et al. Collective chemotaxis requires contact-dependent cell polarity. Dev Cell 19, 39-53 (2010).

105. Becker, S.F., Mayor, R. \& Kashef, J. Cadherin-11 mediates contact inhibition of locomotion during Xenopus neural crest cell migration. PLoS ONE 8, e85717 (2013).

106. Barriga, E.H., Maxwell, P.H., Reyes, A.E. \& Mayor, R. The hypoxia factor Hif-1alpha controls neural crest chemotaxis and epithelial to mesenchymal transition. J Cell Biol 201, 759-76 (2013).

107. Astin, J.W. et al. Competition amongst Eph receptors regulates contact inhibition of locomotion and invasiveness in prostate cancer cells. Nat Cell Biol 12, 1194-204 (2010).

This paper addresses a long standing question concerning the loss of contact inhibition of locomotion between malignant and normal cells. The authors show that different cells express distinct levels of Eph and their receptors, which could lead to activation or inhibition of $\mathrm{Cdc42}$, promoting or inhibiting cell migration.

108. Batson, J., Maccarthy-Morrogh, L., Archer, A., Tanton, H. \& Nobes, C.D. EphA receptors regulate prostate cancer cell dissemination through Vav2-RhoA mediated cellcell repulsion. Biol Open 3, 453-62 (2014).

109. Villar-Cervino, V. et al. Contact repulsion controls the dispersion and final distribution of Cajal-Retzius cells. Neuron 77, 457-71 (2013).

This paper highlights the role of contact repulsion mediated by Eph/ephrin interactions in controling the directed migration of Cajal-Retzius cells in the cerebral cortex.

110. Carmona-Fontaine, C., Matthews, H. \& Mayor, R. Directional cell migration in vivo: Wnt at the crest. Cell Adh Migr 2, 240-2 (2008).

111. Mayor, R. \& Theveneau, E. The role of the non-canonical Wnt-planar cell polarity pathway in neural crest migration. Biochem J 457, 19-26 (2014).

112. Matthews, H.K. et al. Directional migration of neural crest cells in vivo is regulated by Syndecan-4/Rac1 and non-canonical Wnt signaling/RhoA. Development 135, 1771-80 (2008).

113. Shnitsar, I. \& Borchers, A. PTK7 recruits dsh to regulate neural crest migration. Development 135, 4015-24 (2008).

114. Witzel, S., Zimyanin, V., Carreira-Barbosa, F., Tada, M. \& Heisenberg, C.P. Wnt11 controls cell contact persistence by local accumulation of Frizzled 7 at the plasma membrane. J Cell Biol 175, 791-802 (2006).

115. Bin-Nun, N. et al. PTK7 modulates Wnt signaling activity via LRP6. Development 141, 410-21 (2014). 
116. Hayes, M., Naito, M., Daulat, A., Angers, S. \& Ciruna, B. Ptk7 promotes non-canonical Wnt/PCP-mediated morphogenesis and inhibits Wnt/beta-catenin-dependent cell fate decisions during vertebrate development. Development 140, 1807-18 (2013).

117. Peradziryi, H. et al. PTK7/Otk interacts with Wnts and inhibits canonical Wnt signalling. Embo J 30, 3729-40 (2011).

118. Theveneau, E. \& Mayor, R. Cadherins in collective cell migration of mesenchymal cells. Curr Opin Cell Biol 24, 677-84 (2012).

119. Moore, R. et al. Par3 controls neural crest migration by promoting microtubule catastrophe during contact inhibition of locomotion. Development 140, 4763-75 (2013).

120. Theveneau, E. \& Mayor, R. Integrating chemotaxis and contact-inhibition during collective cell migration: Small GTPases at work. Small GTPases 1, 113-117 (2010).

121. Desai, R.A., Gopal, S.B., Chen, S. \& Chen, C.S. Contact inhibition of locomotion probabilities drive solitary versus collective cell migration. $J R$ Soc Interface 10, 20130717 (2013).

122. Kashef, J. et al. Cadherin-11 regulates protrusive activity in Xenopus cranial neural crest cells upstream of Trio and the small GTPases. Genes Dev 23, 1393-8 (2009).

123. Davis, J.R. et al. Inter-cellular forces orchestrate contact inhibition of locomotion. Cell 161, 361-73 (2015).

124. Ulmer, B. et al. Calponin 2 acts as an effector of noncanonical Wnt-mediated cell polarization during neural crest cell migration. Cell Rep 3, 615-21 (2013).

125. Theveneau, E. et al. Chase-and-run between adjacent cell populations promotes directional collective migration. Nat Cell Biol 15, 763-72 (2013).

This paper shows that neural crest cells control the position of the cells that secrete the chemoattractant Sdf1. Neural crest are attracted towards Sdf1 but induce a repulsion in the cells that secret it, leading to a "chase-and-run" mechanism, with a robust effect on directional migration.

126. Martin, K., Vilela, M., Jeon, N.L., Danuser, G. \& Pertz, O. A growth factor-induced, spatially organizing cytoskeletal module enables rapid and persistent fibroblast migration. Dev Cell 30, 701-16 (2014).

This study shows that in absence of chemotactic gradient, PDGF can induce directed migration of fibroblasts if cells are prepolarized by adhesion on a line of fibronectin. This indicates that the cells can integrate chemical and physical independent cues to migrate in a directed manner.

127. Woods, M.L. et al. Directional collective cell migration emerges as a property of cell interactions. PLoS ONE 9, e104969 (2014).

128. Camley, B.A. et al. Polarity mechanisms such as contact inhibition of locomotion regulate persistent rotational motion of mammalian cells on micropatterns. Proc Natl Acad Sci US A 111, 14770-5 (2014).

129. Li, J.F. \& Lowengrub, J. The effects of cell compressibility, motility and contact inhibition on the growth of tumor cell clusters using the Cellular Potts Model. $J$ Theor Biol 343, 79-91 (2014).

130. Fulga, T.A. \& Rorth, P. Invasive cell migration is initiated by guided growth of long cellular extensions. Nat Cell Biol 4, 715-9 (2002).

131. Cai, D. \& Montell, D.J. Diverse and dynamic sources and sinks in gradient formation and directed migration. Curr Opin Cell Biol 30, 91-8 (2014). 
132. Malet-Engra, G. et al. Collective cell motility promotes chemotactic prowess and resistance to chemorepulsion. Curr Biol 25, 242-50 (2015).

133. David, N.B. et al. Molecular basis of cell migration in the fish lateral line: role of the chemokine receptor CXCR4 and of its ligand, SDF1. Proc Natl Acad Sci U S A 99, 16297-302 (2002).

134. Kerstetter, A.E., Azodi, E., Marrs, J.A. \& Liu, Q. Cadherin-2 function in the cranial ganglia and lateral line system of developing zebrafish. Dev Dyn 230, 137-43 (2004).

135. Dambly-Chaudiere, C., Cubedo, N. \& Ghysen, A. Control of cell migration in the development of the posterior lateral line: antagonistic interactions between the chemokine receptors CXCR4 and CXCR7/RDC1. BMC Dev Biol 7, 23 (2007).

136. Valentin, G., Haas, P. \& Gilmour, D. The chemokine SDF1a coordinates tissue migration through the spatially restricted activation of Cxcr7 and Cxcr4b. Curr Biol 17, 1026-31 (2007).

137. Aman, A. \& Piotrowski, T. Cell migration during morphogenesis. Dev Biol 341, 20-33 (2010).

138. Dona, E. et al. Directional tissue migration through a self-generated chemokine gradient. Nature 503, 285-9 (2013).

139. Muinonen-Martin, A.J. et al. Melanoma cells break down LPA to establish local gradients that drive chemotactic dispersal. PLoS Biol 12, e1 001966 (2014).

This paper demonstrates that melanoma cells break down LPA, generating a LPA gradient, that works as a chemoattractant for the migration of these cells.

140. Theveneau, E. \& Mayor, R. Neural crest delamination and migration: from epithelium-tomesenchyme transition to collective cell migration. Dev Biol 366, 34-54 (2012).

141. Mayor, R. \& Theveneau, E. The neural crest. Development 140, 2247-51 (2013).

142. Costantini, F. \& Kopan, R. Patterning a complex organ: branching morphogenesis and nephron segmentation in kidney development. Dev Cell 18, 698-712 (2010).

143. Dalle Nogare, D. et al. Leading and trailing cells cooperate in collective migration of the zebrafish posterior lateral line primordium. Development 141, 3188-96 (2014).

References 138 and 143 show that leader and follower cells of the lateral line primordium can self-generate gradients of chemokine activity to promote the directed collective migration of the primordium. Expression of $\mathrm{Cxcr} 7 \mathrm{~b}$ in trailing cells prevents $\mathrm{Cxcr} 4 \mathrm{~b}$ signaling in these cells, inducing the polarized response of the primordium to the Cxcl12 and promoting unidirectional migration of the cell group. [Au:OK?yes]

144. Bhowmick, N.A., Neilson, E.G. \& Moses, H.L. Stromal fibroblasts in cancer initiation and progression. Nature 432, 332-7 (2004).

145. Pietras, K. \& Ostman, A. Hallmarks of cancer: interactions with the tumor stroma. Exp Cell Res 316, 1324-31 (2010).

146. Szabo, A. \& Mayor, R. Cell traction in collective cell migration and morphogenesis: the chase and run mechanism. Cell Adh Migr In press (2015).

147. Choe, C.P. \& Crump, J.G. Eph-Pak2a signaling regulates branching of the pharyngeal endoderm by inhibiting late-stage epithelial dynamics. Development 142, 1089-94 (2015).

148. Breau, M.A. \& Schneider-Maunoury, S. Cranial placodes: models for exploring the multifacets of cell adhesion in epithelial rearrangement, collective migration and neuronal movements. Dev Biol 401, 25-36 (2015). 
149. Attia, L., Schneider, J., Yelin, R. \& Schultheiss, T.M. Collective cell migration of the nephric duct requires FGF signaling. Dev Dyn 244, 157-67 (2015).

150. Shamir, E.R. \& Ewald, A.J. Adhesion in mammary development: novel roles for Ecadherin in individual and collective cell migration. Curr Top Dev Biol 112, 353-82 (2015).

151. Wang, J., Cao, J., Dickson, A.L. \& Poss, K.D. Epicardial regeneration is guided by cardiac outflow tract and Hedgehog signalling. Nature 522, 226-30 (2015).

152. Gerhardt, H. et al. VEGF guides angiogenic sprouting utilizing endothelial tip cell filopodia. J Cell Biol 161, 1163-77 (2003).

153. Duchek, P. \& Rorth, P. Guidance of cell migration by EGF receptor signaling during Drosophila oogenesis. Science 291, 131-3 (2001).

154. Duchek, P., Somogyi, K., Jekely, G., Beccari, S. \& Rorth, P. Guidance of cell migration by the Drosophila PDGF/VEGF receptor. Cell 107, 17-26 (2001).

155. McDonald, J.A., Pinheiro, E.M. \& Montell, D.J. PVF1, a PDGF/VEGF homolog, is sufficient to guide border cells and interacts genetically with Taiman. Development 130, 3469-78 (2003).

156. McDonald, S.A., Preston, S.L., Lovell, M.J., Wright, N.A. \& Jankowski, J.A. Mechanisms of disease: from stem cells to colorectal cancer. Nat Clin Pract Gastroenterol Hepatol 3, 267-274 (2006).

157. Ghysen, A., Dambly-Chaudiere, C. \& Raible, D. Making sense of zebrafish neural development in the Minervois. Neural Dev 2, 15 (2007).

158. Carmona-Fontaine, C. et al. Complement fragment C3a controls mutual cell attraction during collective cell migration. Dev Cell 21, 1026-37 (2011).

159. Vignjevic, D. et al. Fascin, a novel target of beta-catenin-TCF signaling, is expressed at the invasive front of human colon cancer. Cancer Res 67, 6844-53 (2007).

160. Wolf, K. et al. Multi-step pericellular proteolysis controls the transition from individual to collective cancer cell invasion. Nat Cell Biol 9, 893-904 (2007).

161. Etienne-Manneville, S. Actin and microtubules in cell motility: which one is in control? Traffic 5, 470-477 (2004).

162. Jacinto, A., Martinez-Arias, A. \& Martin, P. Mechanisms of epithelial fusion and repair. Nat. Cell Biol. 3, E117-123 (2001).

163. Wicki, A. et al. Tumor invasion in the absence of epithelial-mesenchymal transition: podoplanin-mediated remodeling of the actin cytoskeleton. Cancer Cell 9, 261-72 (2006).

164. McLennan, R. et al. Multiscale mechanisms of cell migration during development: theory and experiment. Development 139, 2935-44 (2012).

165. Feng, Q. et al. Cool-1 functions as an essential regulatory node for EGFreceptor- and Srcmediated cell growth. Nat Cell Biol 8, 945-56 (2006).

166. Etienne-Manneville, S. Cdc42--the centre of polarity. J Cell Sci 117, 1291-300 (2004).

167. Etienne-Manneville, S. \& Hall, A. Cell polarity: Par6, aPKC and cytoskeletal crosstalk. Curr. Opin. Cell Biol. 15, 67-72 (2003).

168. Gomes, E.R., Jani, S. \& Gundersen, G.G. Nuclear movement regulated by Cdc42, MRCK, myosin, and actin flow establishes MTOC polarization in migrating cells. Cell 121, 451-63 (2005).

169. Watson, L.J., Rossi, G. \& Brennwald, P. Quantitative analysis of membrane trafficking in regulation of Cdc42 polarity. Traffic 15, 1330-43 (2014).

170. Cau, J. \& Hall, A. Cdc42 controls the polarity of the actin and microtubule cytoskeletons through two distinct signal transduction pathways. J Cell Sci 118, 2579-87 (2005). 
171. Nola, S. et al. Scrib regulates PAK activity during the cell migration process. Hum Mol Genet 17, 3552-65 (2008).

172. Daub, H., Gevaert, K., Vandekerckhove, J., Sobel, A. \& Hall, A. Rac/Cdc42 and p65PAK regulate the microtubule-destabilizing protein stathmin through phosphorylation at serine 16. J. Biol. Chem. 276, 1677-1680 (2001).

173. Dupin, I. \& Etienne-Manneville, S. Nuclear positioning: mechanisms and functions. Int $J$ Biochem Cell Biol 43, 1698-707 (2011).

\section{Glossary terms:}

Adherens junctions: molecular complexes allowing intercellular interaction. They involve the homophilic interaction of classical cadherins and a large complex of cytosolic proteins, such as catenins, bridging cadherins to the cytoskeleton, including actin stress fibers.

Chemotaxis: process by which cells undergo directed locomotion along a chemical gradient.

Filopodia: Finger-like membrane projection frequently found at the leading edge of migrating cells. These membrane protrusions are formed by the polymerization of actin bundles and can, in particular, be induced by the small GTPase Cdc42.

Focal adhesions: molecular complexes allowing cell adhesion to the extracellular matrix. They involve the transmembrane protein integrins, and a large complex of cytosolic proteins bridging integrins to the cytoskeleton, including actin stress fibers.

Integrin: Familly of transmembrane proteins involved in cell interaction with protein fibers of the extracellular matrix (ECM). $\alpha$ and $\beta$ integrins form heterodimers whose conformation and affinity for the ECM is regulated by inside-out signaling. Upon engagement with the ECM, integrin dimers induce intracellular (outside-in) signaling.

Lamellipodia: thin sheet-like membrane extension frequently found at the front of migrating cells. The formation of lamellipodia involves the polymerization of a branched actin meshwork and the formation of transient adhesions with the cell substrate.

Nurse cells: cells which contribute to the development of the oocyte of invertebrate organisms. In Drosophila melanogaster, 15 nurse cells are included in the egg chamber provides the nutrients, RNA and proteins required for the oocyte growth. 
Desmosome: cell-cell adhesion complex typically found in epithelial cells. Desmosomes involve specific members of the cadherin family of transmembrane adhesion proteins and are connected to keratin filaments.

\section{Online summary:}

- During collective migration, cells not only migrate in a coordinated manner, they also migrate faster and in a more directed way than individual cells. Coordination and efficiency of collective migration rely on cellular interactions through soluble and contact-mediated signals.

- Leader cells, generally localized at the front of the migrating group, present specific molecular features and morphological characteristics, which are reinforced by the soluble and contactmediated signals present in their microenvironment..

- Leader cells facilitate the directed migration of followers directly by generating pulling forces and indirectly by modifying the extracellular matrix composition and structure.

- Intercellular contacts between collectively migrating cells involving several sets of membrane proteins, induce a local inhibition of locomotion through the regulation of Rho GTPases. Contact inhibition of locomotion is an essential event promoting the coordinated polarization of collectively migrating cells.

- Several lines of evidence have shown that the followers actively participate to the collective movement by communicating with one another and with the leaders, by generating forces, by contributing to generation of chemotactic gradients. 


\section{Display items}

\section{Box 1 | Collective cell migration in vivo}

Cells that undergo collective migration are commonly found in vivo, in the pharyngeal endoderm ${ }^{147}$, cranial placodes ${ }^{148}$, nephric ducts ${ }^{149}$, and during mammary branching morphogenesis ${ }^{150}$, hear regeneration ${ }^{151}$ and angiogenesis ${ }^{152}$. Four well-studied in vivo models are:

Border cell in Drosophila melanogaster (see the figure, part a): The ovary is composed of ovarioles and the egg chamber. In the egg chamber contains one oocyte and several support cells, which are surrounded by epithelial follicle cells. During oogenesis, anterior polar cells (purple) recruit neighbor cells to form the border cell cluster and start their migration. One or two leading cells extend protrusions in response to the chemoattractants PVF1, Spitz and Karen, secreted by the oocyte ${ }^{153-156}$, and Gurken, localized at the dorsal-anterior corner of the oocyte ${ }^{153,155,156}$. DEcadherin (pink) plays distinct roles during border cell migration, and it functions in a positive loop with $\operatorname{Rac} 1^{62}$.

Lateral line in zebrafish (see the figure, part b): The primordium of the zebrafish lateral line is formed by a cluster of more than 100 cells that migrate from the head to the tail of the embryos, where it forms series of rosette-like mechanosensory organs ${ }^{157}$. The primordium migrates as a compact epithelial cluster with large polarized protrusions at the front. The direction of migration is determined by a self-generated gradient of Sdf1 (see also Fig 5a) ${ }^{136,137,157 .}$

Neural crest in Xenopus laevis (see the figure, part c): cephalic neural crests are formed in the dorsal part of the neural tube and migrate ventrally contributing to many head structures ${ }^{141}$. The cephalic neural crest undergoes an epithelial to mesenchyme transition (during which E-cadherin disappears) but still migrates as a cohesive cluster of cells that influence each other behavior ${ }^{104}$. The cluster configuration is maintained mainly by chemotaxis between neighbor cells, instead of cell adhesion (chemoattractant $\mathrm{C} 3 \mathrm{a}$, blue circles ${ }^{158}$ ).

Cancer invasion (see the figure, part d): during metastasis cancer cells spread from one organ to another (e.g. melanomas from the skin of a hand can spread to different organs on the body). This spreading can involve collective cell migration; which is usually found in epithelial cancers; although leader cells can acquire a more mesenchymal phenotype with cell generating 
protrusions and activating Rac1. Often cell clusters migrate following some physical clues, such as collage fibers, myofibrils, basal lamina from muscles, nerves or blood vessels ${ }^{2}$.

\section{Box 2 The place of leader cells during collective migration}

Because of their localization at the front, leader cells (shown in green, see the figure, panels a-f) have a contact-free edge that can form and extend protrusions, unlike lateral and rear sides that are involved in cell-cell contacts. Moreover, followers are all equivalent when the cells migrate in unlimited sheets or chains (that is, without a defined rear) (see the figure, panels a-c), whereas the followers that are located at the rear of limited cell groups (see the figure, panels d-f) have a rear side which is not involved in cell-cell contact. These different examples of collective cell migration configurations also illustrate the fact that the number of leader cells varies depending on the context, and in particular with the geometry of the migrating group. The collective migration of cell monolayers, for example during fibroblast or astrocyte wound healing in vitro, and dorsal closure in Drosophila melanogaster is driven by a first row of leader cells (as represented in part a) or by clustered leader cells localized at the front edge, as is the case during epithelial wound healing in vitro] (as represented in part b). Similarly limited numbers of leader cells have been identified in broad fronts of invasive cancer ${ }^{26,159}$. One or two leader cells, also called tip-cells (part c), are sufficient to guide the collective migration of strands of cells (for example endothelial cells during angiogenesis or tracheal development) or cell groups as observed during cancer invasion ${ }^{72,160}$ (panel d). During the lateral line primordium migration in zebrafish, a group of 10 to 20 leader cells guide the primordium along a path of Sdf1 secreting stromal cells (panel e), whereas a single cell leads the migration of the small cluster of $D$. melanogaster border cells (panel f). 
Figure 1 Polarization in single cells and in collectively migrating cells.

\section{a | Front-to-rear polarization during single cell migration}

During single cell migration the main engine for movement seems to be at the front of the cell, where active membrane protrusion occurs and the cell adheres to the ECM. As the lamellipodia extends, integrin-based nascent adhesions form to eventually mature in focal adhesions, on which longitudinal acto-myosin cables are anchored. Mature focal adhesions are maintained during migration until they reach the retracting edge of the cells, where they are disassembled. For clarity, only a few nascent and mature adhesions are shown. Locomotive forces applied to focal adhesions drive movement of the cell on or through the substratum. While events at the cell leading edge provide essential forces for forward movement, the cell rear also actively participates to cell displacement by controlling the detachment from the ECM and the contraction of the cell body. The microtubule network and intracellular membrane compartments also organize in a polarized manner along the direction of migration.

\section{b | Polarization in a group of collectively migrating cells}

Reflecting this front-rear orientation, leader cells are clearly polarized : they show an elongated morphology, polarized along the direction of migration ${ }^{89,161,162}$. This polarization has been observed in vitro during wound healing and in vivo during the migration of Xenopus laevis head mesoderm, lateral line in zebrafish, border cells in Drosophila melanogaster, cephalic neural crest and others ${ }^{101}$. However, observations in vitro show that some wound-edge Mammalian epithelial cells elongate more than others and some epithelia leader cells can spread perpendicularly to the direction of migration ${ }^{7,15}$. The increased spreading of leader cells associated with a mesenchymal phenotype reflects a transient loss or reorientation of epithelial baso-apical polarity in favor of a front-rear polarity ${ }^{89}$. However, leaders retain some epithelial characteristics, remaining attached to their neighbors. Leaders often display dynamic actin-based protrusive structures. Although not limited to leader cells, finger-like filopodia and ruffling lamellipodia form at the front edge of the epithelial monolayer ${ }^{7}$ as well as at the leading edge of tip cells initiating vascular sprouts in mammals and tracheal branches in D. melanogaster. The morphology of leader cells is associated with the expression of specific genes which promote cytoskeleton remodeling and cell migration $^{159,163,164}$. 
c Polarizing environmental cues. In a cohesive cell group, the leader cells are submitted to polarized environmental cues. While the cell rear is engaged in intercellular contacts, the cell front interacts with the extracellular matrix or with non-migrating cells of the tissue. Adherens junctions by locally inhibiting the formation and maintenance of focal adhesions ${ }^{56,57}$ restrict the localization of focal adhesion to the cell front.

Figure 2 | Polarization of leader cells by integrin-induced signaling. a | During in vitro woundinduced cell migration, integrin signaling leads to the recruitment at the leading edge plasma membrane of the polarity protein Scrib which interacts with the Rac and Cdc42 GEF $\beta$ PIX ${ }^{17}$. Phosphorylation of $\beta$ PIX by Src promotes its Cdc42 GEF activity ${ }^{165}$. Cdc42 contributes to the reorganization of the microtubule network ${ }^{23,166}$. Cdc42 activates the polarity complex formed of Par6 and aPKC which in turn induces microtubules anchoring and centrosome and Golgi positioning in front of the nucleus ${ }^{167}$. MRCK also contributes to the Cdc42-dependent retrograde flow of actin fibers leading to the rearward nuclear movement ${ }^{168}$. Reorganization of membrane traffic towards the leading edge is likely to participate to the formation of membrane protrusion, the development of new adhesions and the reinforcement of polarity signaling ${ }^{16,169}$. b $\mid$ Via its SH3 domain, leading edge $\beta$ PIX also recruits Rac and PAK ${ }^{170,171}$. Rac can be activated by PI3K as several Rac GEFs are activated by PIP3. Alternatively, the Rac GEF Tiam1, possibly associated with Par3 and PKCzeta, also promotes Rac activation, cell migration and tumor invasion $^{18,19,38}$. Active Rac control actin-driven protrusion ${ }^{22}$ and microtubule elongation through $\mathrm{PAK}^{172}$. The schematics represent a cell migrating in a flat $2 \mathrm{D}$ rigid substrate. Similar integrinmediated signaling cascade is likely to occur in a 3D environment although the contribution of integrin signaling varies with the substrate rigidity. In addition to variation in intracellular signaling, the geometry of the 3D environment profoundly impact on the cell protrusion morphology.

Figure 3 | Role and dynamics of adherens junctions between leader cells. a | The anisotropic distribution of adherens junctions in leader cells induces the anisotropic distribution of focal adhesions. This induces a polarized integrin-mediated signaling which leads to the orientation of 
the cytoskeleton, the centrosome and the Golgi apparatus towards the cell front and participates to the coordination of the migration direction between leader cells. $\mathbf{b} \mid$ Lateral adherens junctions are tightly linked to transverse acto-myosin cables and contribute to a multicellular actin network. These transverse actin cables move together in a retrograde flow (black arrows), which may coordinate the actin dynamics in neighboring cells and contributes to cadherin-dependent positioning of the nucleus ${ }^{56,173}$. $\mathbf{c} \mid$ The retrograde flow of adherens junctions allows the dynamic rearrangement of cell-cell contacts when cells move around obstacles (such as cells or matrix fibers). Cadherin recycling which compensates the retrograde flow of junctions leads to cadherin accumulation at the leading edge. This pool of cadherin can immediately be recruited to sites of new cell contacts during cell collision and thus contribute to contact inhibition of locomotion.

Figure 4 | Contact inhibition of locomotion (CIL). a | CIL is the process by which a cell change the direction of migration upon collision with another cell (a,top right), which lead to cell polarization, with protrusion being inhibited at the cell contact and new protrusion produced away from the contact. If cell density increases a similar phenomenon of inhibition of protrusion at the cell contact takes place, but at a larger scale, where only the cells exposed to the free edge become polarized and produce protrusions away from the cluster (a, left). Cell contact during CIL is indicated with a red square. b | Molecular mechanism of CIL. Cell surface molecules interact at the site of cell-cell contact (red square), which leads to the recruitment of several other proteins and finally RhoA activation and Rac inhibition at the contact. This is translated into microtubule catastrophe, disassemble of focal adhesions (white circles) and actomyosin contractility at the contact, leading to protrusions collapse. At the opposite end of the cell activation of Rac leads to microtubule and microfilament polymerization and stabilization of focal adhesions (red circles), with the consequent formation of protrusion.

Figure 5 | Self-generated chemoattractants gradients during collective cell migration. a | Anterior and posterior domains of the zebrafish lateral line primordium express the Sdf1 receptor Cxcr4 (green), whereas only posterior cells express the scavenger Sdf1 receptor Cxcr7 (red). Initially (top frame) Sdf1 (blue, blue circles) is expressed uniformly along the primordium. Binding of Sdf1 to the Cxcr7 receptor works as a sink for Sdf1 generating a sharp gradient of Sdf1 (middle panel). Cells move towards higher level of Sdf1 present in the anterior end of the primordium (bottom panel). b | Neural crest (grey cluster) chemotax towards Sdf1 (blue 
background) secreted by placode cells (pink cluster) (top panel). When neural crest reaches the placode (middle panel) they trigger a CIL response (red line) forcing the placode to move away, and the neural crest cells then follow (bottom panel). $\mathbf{c} \mid$ Melanoma cells can chemotax towards LPA (blue background) which is distributed homogenously in the extracellular medium (top panel). Melanoma cells degrade LPA generating a gradient with concentrations low next to the cells and higher away from them (middle panel). Melanoma cells sense this LPA gradient and move accordingly (bottom panel).

\section{Biographies:}

Roberto Mayor:

Roberto Mayor is professor of Cell and Developmental Neurobiology at the Cell and Developmental Biology Department, University College London. He obtained his PhD in 1990 from the University of Chile working on preimplantation mouse development. After that he started his postdoctoral training at the National Institute for Medical Research in London, UK working on Xenopus laevis in the laboratory of Dr. Michael Sargent, where he showed that the Snail genes are expressed and play an important role on neural crest development in the frog. $\mathrm{He}$ moved to Chile in 1993 as a group leader where he pursued studied on neural crest induction. In 2004 he got an independent leader position at University College London, where he started his current work on neural crest migration, demonstrating that neural crest exhibit collective cell migration and contact inhibition of locomotion .

\section{Sandrine Etienne-Manneville:}

Sandrine Etienne-Manneville is Directrice de Recherche at the CNRS and professor at Ecole Polytechnique (Palaiseau, France). She studied cell Biology and biochemistry at the Ecole Normale Supérieure in Paris and obtained her PhD in Immunology in 1998, working on the regulation of leukocyte infiltration in the central nervous system. During her four years of postdoctoral training in the laboratory of Prof A.Hall at the MRC-LMCB in London, she deciphered Cdc42-mediated polarity pathways during astrocyte directed migration. In 2003 she obtained a CNRS position at the Curie Institute (Paris, France). In 2006, she moved to the Pasteur 
Institute (Paris, France) as a group leader to pursue her study of astrocyte polarization and migration. Her research team focuses on the molecular mechanisms controlling polarization and migration of normal and tumoral astrocytes.

\section{ToC:}

\section{The front and rear of collective cell migration}

\section{Roberto Mayor and Sandrine Etienne-Manneville}

Collective cell migration has a crucial role during morphogenesis, wound healing and tissue renewal, and it is involved in cancer spreading. Recent studies highlight the importance of intercellular communication in this process: migration is driven by leader cells at the front, and follower cells communicate between them and with the leaders to improve the efficiency of collective movement.

\section{Subject categories:}

Biological sciences / Cell biology / Cell migration / Collective cell migration [URI /631/80/84/2334]

Biological sciences / Cell biology / Cell migration [URI $/ 631 / 80 / 84$ ]

Biological sciences / Cell biology / Cell adhesion [URI $/ 631 / 80 / 79$ ] 
Box 1

a

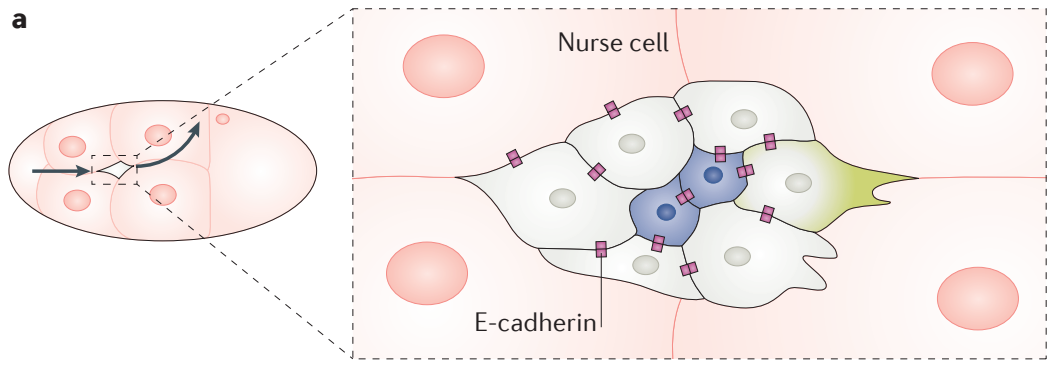

b

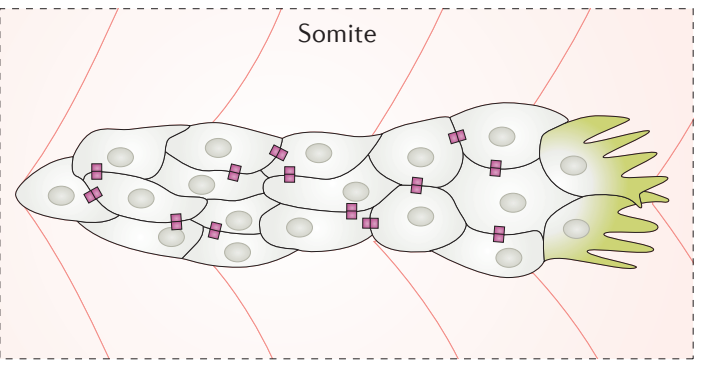

c

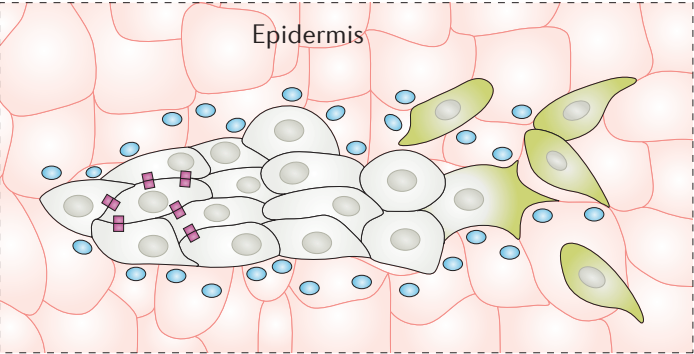

d

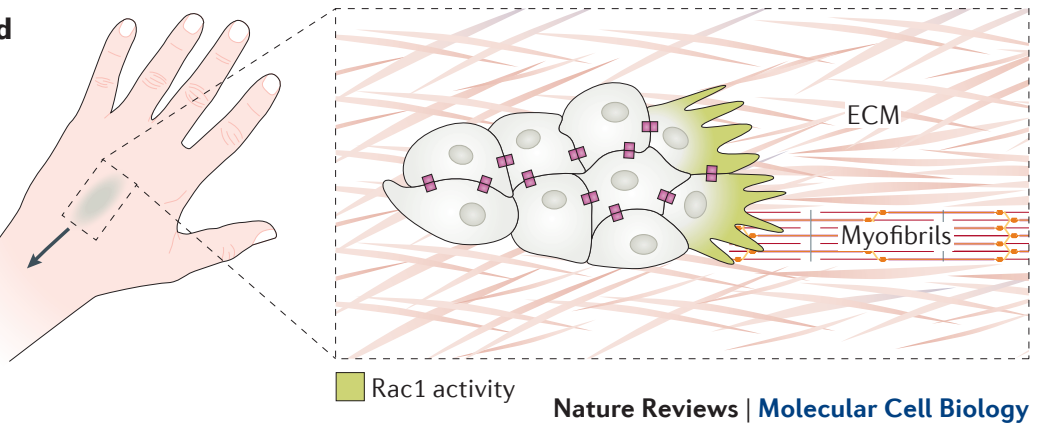


Box 2

a

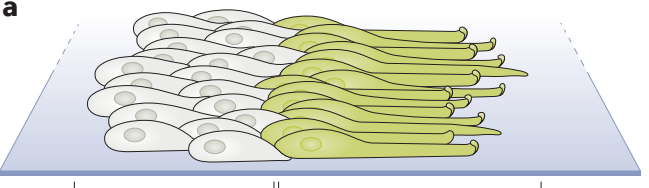

Followers

b

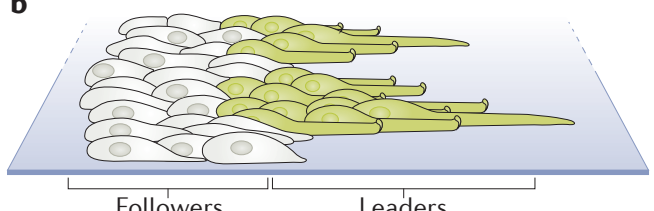

Followers

c

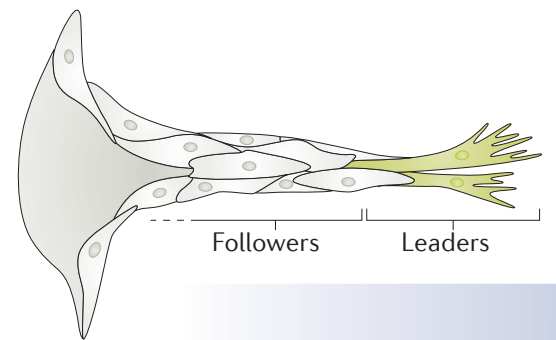

d

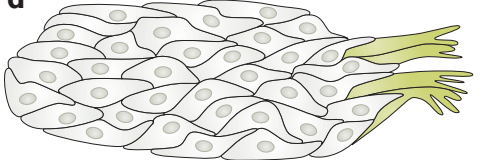

e

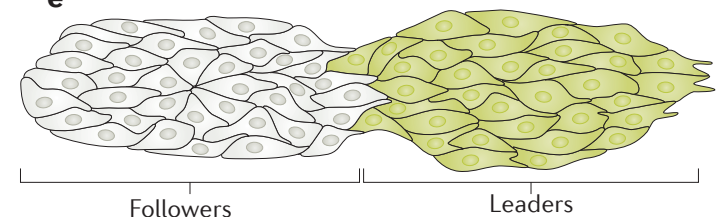

f

Direction of migration 
Fig 1

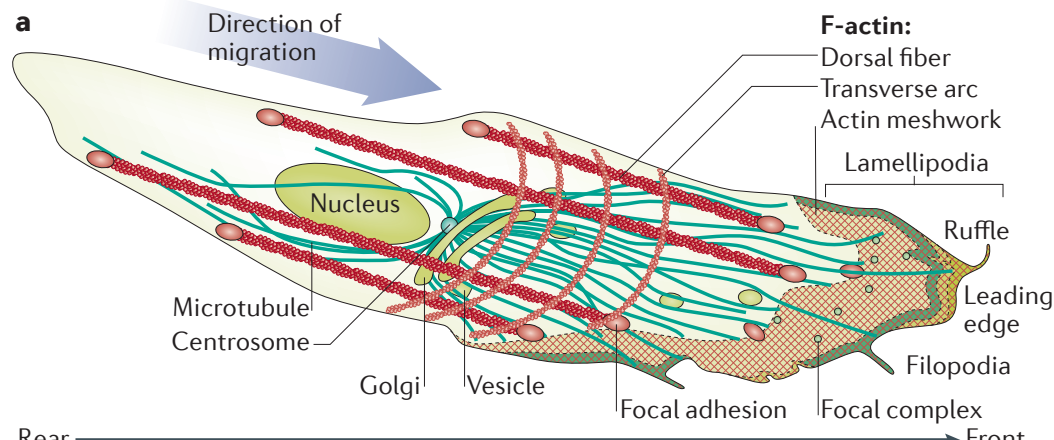

F-actin:

Rear $\longrightarrow$ Polarity axis $\longrightarrow$ Front

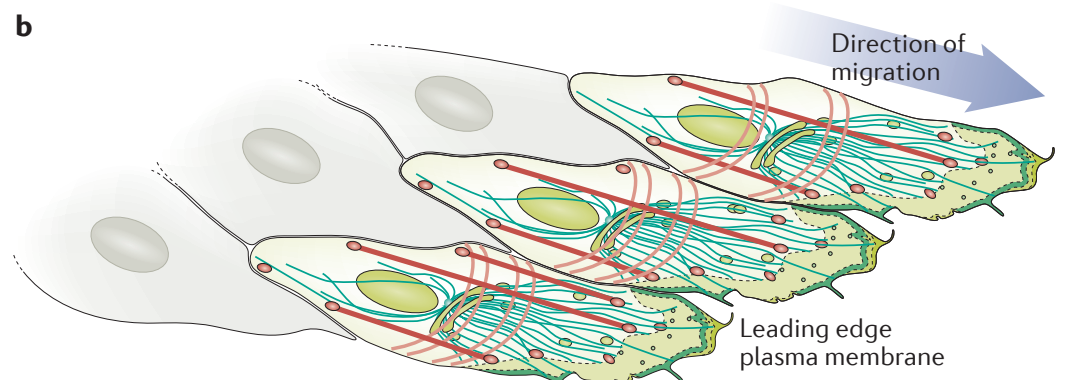

c

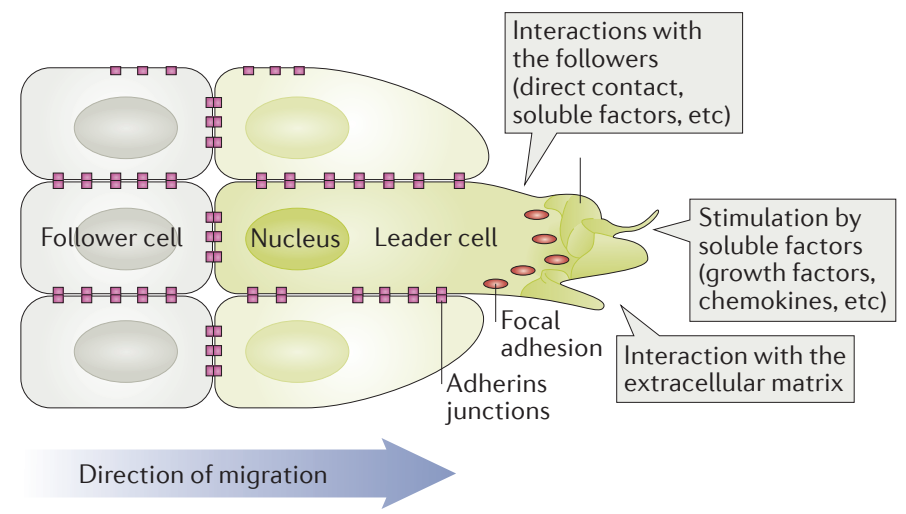

Nature Reviews | Molecular Cell Biology

Fig 2

a Cdc42 signaling

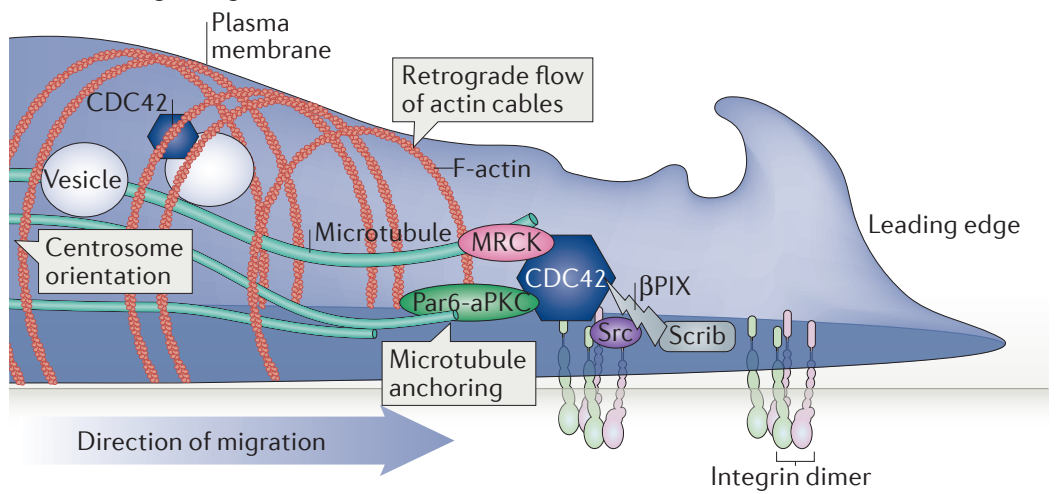

b Rac signaling

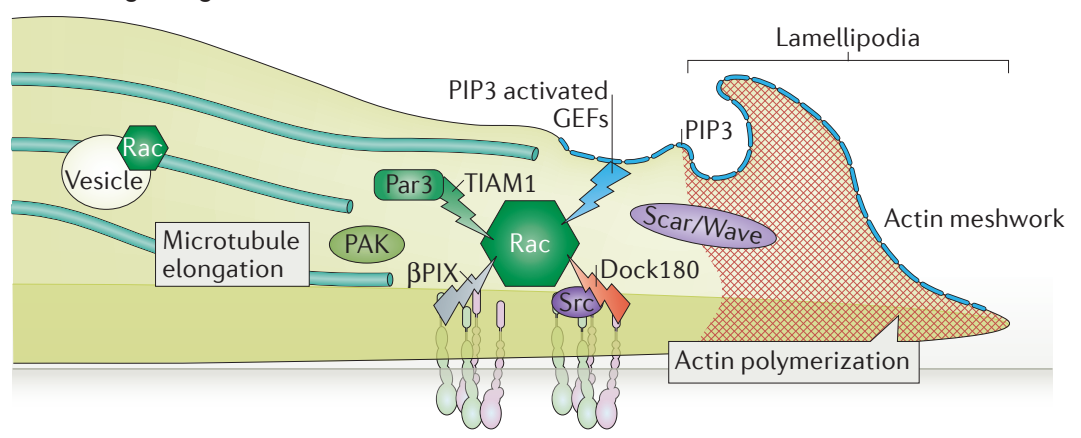

\begin{tabular}{|l}
$\square_{\substack{\text { Scaffold protein } \\
\text { fuanosine exchange }}} \begin{array}{l}\text { Small G protein } \\
\text { (RAc or Cdc42) }\end{array}$ \\
Effector protein
\end{tabular}


Fig 3

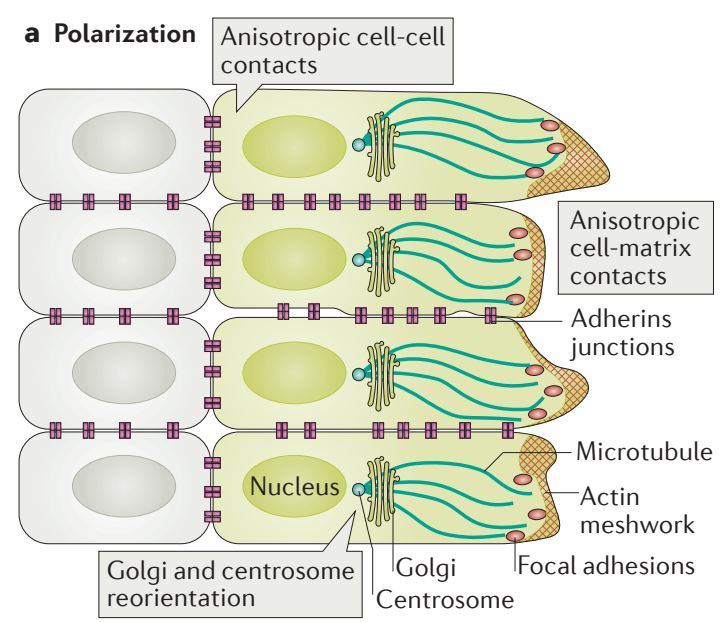

Direction of migration

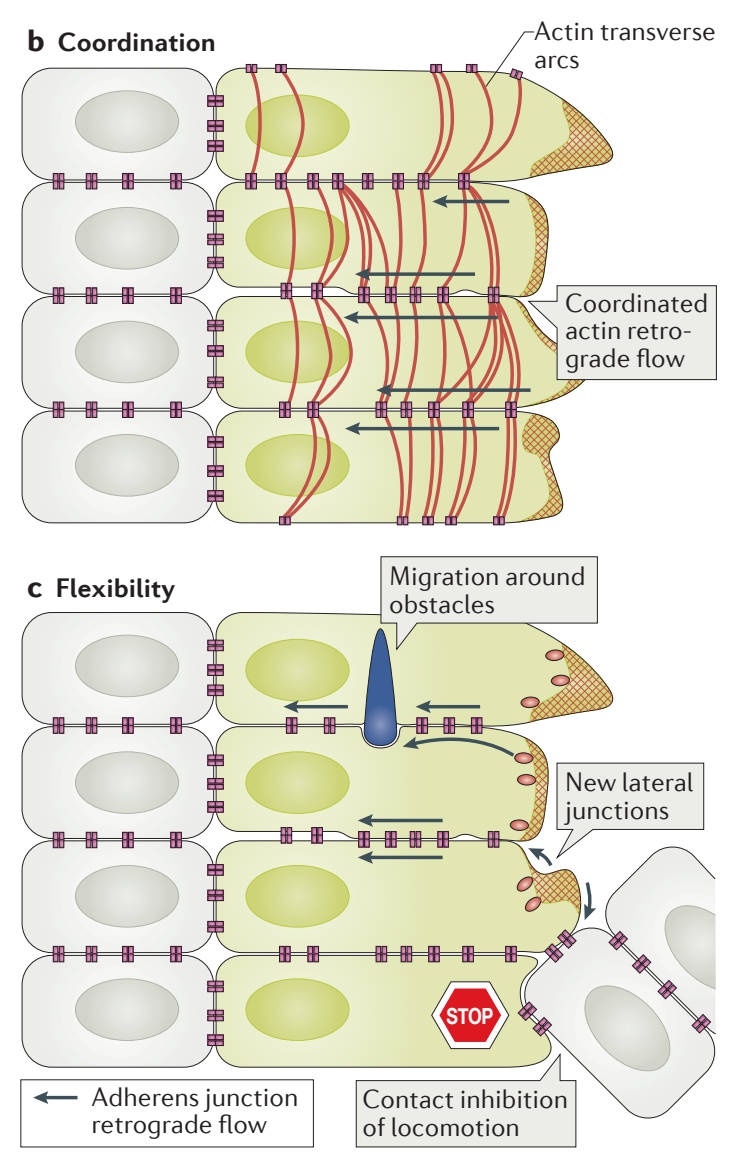

Nature Reviews | Molecular Cell Biology 
Fig 4

a
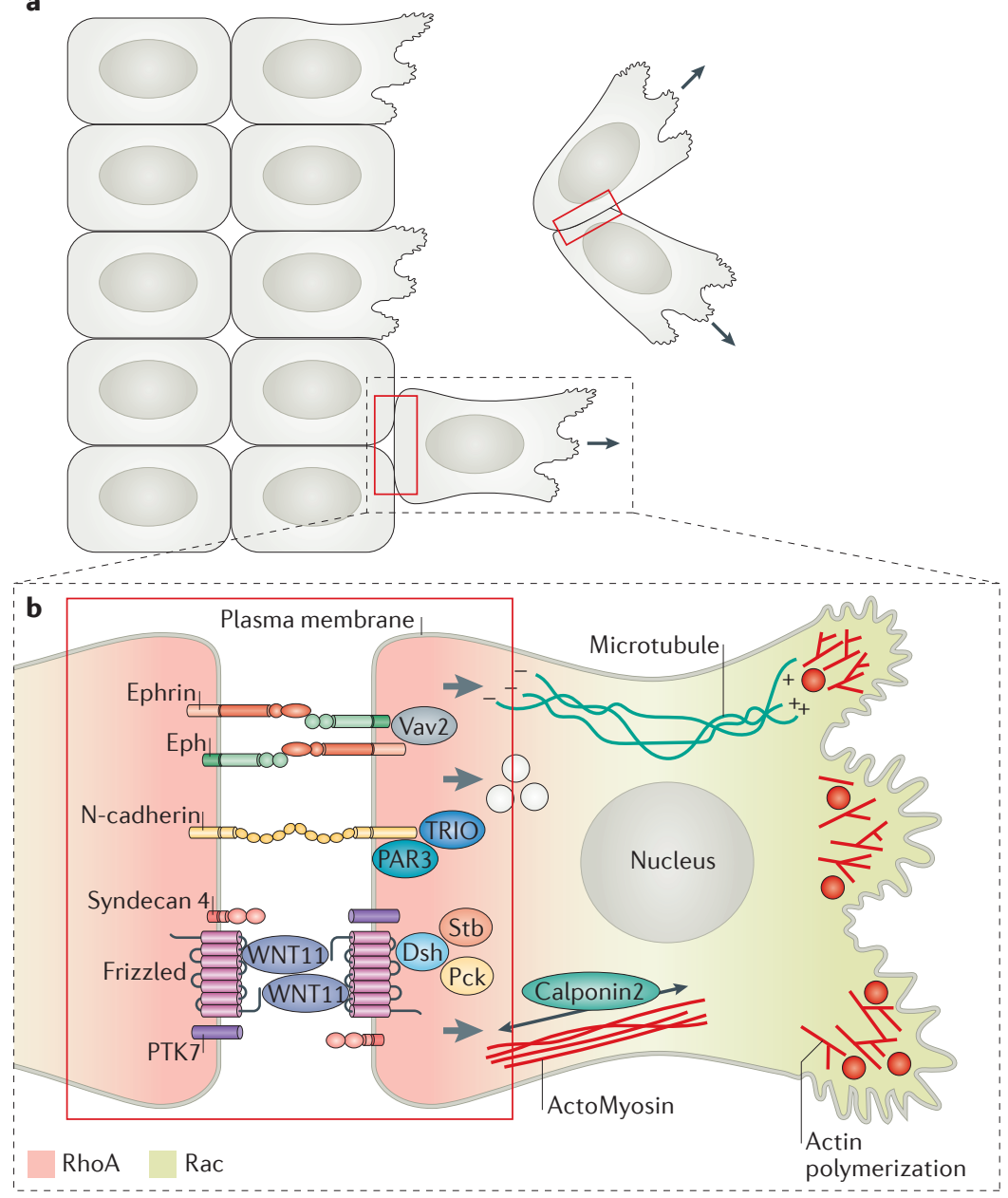

Nature Reviews | Molecular Cell Biology

Fig 5

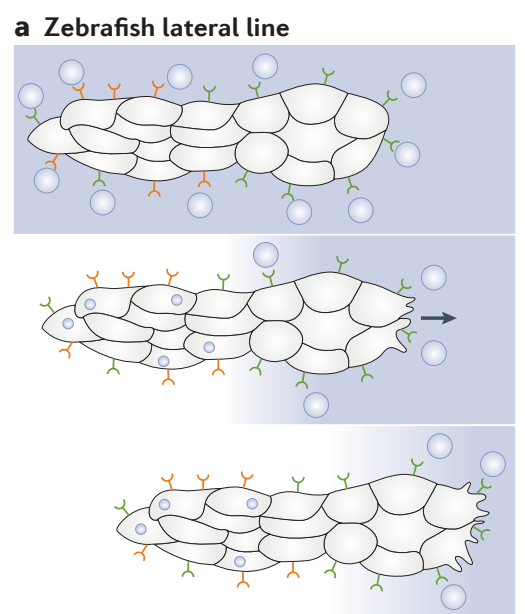

b Frog neural crest
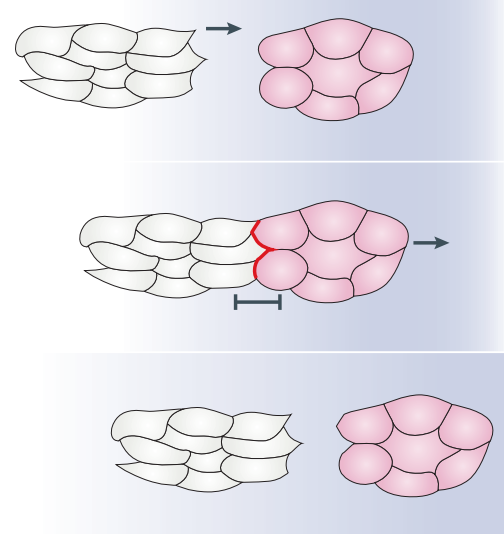

c Melanoma

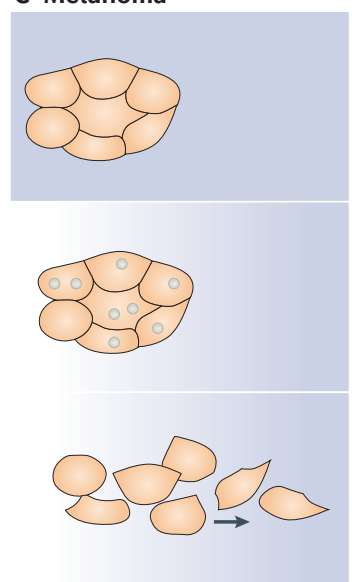

Nature Reviews | Molecular Cell Biology 